\title{
FISCALIDAD Y CONSENSO EN EL VIRREINATO DE PERÚ, 1620-1650
}

\author{
Arrigo Amadori* \\ Universidad Complutense de Madrid, Madrid, España, <aamadori@ghis.ucm.es>
}

Resumen. Este artículo aborda el incremento de la presión fiscal que tuvo lugar en el virreinato de Perú entre 1621 y 1643. A través del análisis de las cuentas de la Caja de Lima se pretende demostrar que, aunque en el corto plazo el avance del poder central se tradujo en el aumento de los ingresos y de las remesas oficiales enviadas desde el Callao a Sevilla, en realidad se trató de un fenómeno transitorio que encubrió sólo de forma temporal la crisis fiscal que atravesó Perú durante parte del siglo XVII. En este marco, se busca poner de manifiesto que el incremento de los ingresos de la tesorería limeña y de las remesas a Castilla dependió estrechamente de la aquiescencia de los grupos de poder local, sobre todo respecto de las nuevas cargas introducidas entre 1627 y 1641, y de la gestión que los virreyes realizaron de los egresos.

Palabras clave: administración fiscal, consenso, negociaciones arancelarias, elite, virreinato.

Abstract. This article looks into the increasing fiscal demands placed on the Viceroyalty of Peru between 1621 and 1643. The aim is to demonstrate through an analysis of the books of the Treasury of Lima, that although advances in central power resulted in a short-term increase in income and official remittances from El Callao to Seville, the rise actually reflected a only a transitory phenomenon that temporarily disguised the fiscal crisis affecting Peru during part of the XVII century. Within this context, the aim is to reveal that the rising revenues of the Treasury of Lima and the remittances to Castile depended heavily on the acquiescence of the local power groups, especially with respect to the new economic burdens introduced between 1627 and 1641 and the viceroys' management of expenditures.

Key words: tax administration, consensus, tariff negotiations, elite, viceroyalty.

Fecha de recepción: diciembre de 2010. Fecha de aceptación: junio de 2011

\footnotetext{
* Quisiera dejar constancia de mi agradecimiento a Pilar Ponce Leiva, Carmen Ruigómez Gómez, Guillermina del Valle Pavón y Pedro Pérez Herrero por sus valiosos comentarios a la primera versión de este artículo.
}

Am. Lat. Hist. Econ., año 19, núm. 2 (38), mayo-agosto, 2012, pp. 7-45 


\section{UNA MONARQUÍA EN EQUILIBRIO}

S uperado el momento inicial de la conquista, la corona puso especial atención en evitar que se reprodujeran en los virreinatos americanos situaciones que pudieran atenuar su capacidad de acción. Uno de sus principales objetivos consistió en impedir la formación de cuerpos representativos que limitaran el poder real. Asimismo procedió a la implantación de lo que Herbert Klein denominó "uno de los sistemas impositivos más modernos conocidos en los albores de la Europa moderna". Sin embargo, pese a que estos objetivos fueron parcialmente alcanzados y que durante varias décadas la historiografía institucional, basándose en un paradigma "estatalista", destacó los avances realizados en América en la concentración del poder, lo cierto es que la relación entre el poder central de la monarquía y el ámbito local resultó bastante más compleja de lo que se había asumido. Los cambios interpretativos que supusieron la paulatina incorporación por parte del americanismo de la profunda renovación de la historia política han ido conformando una visión notablemente más dinámica de dicha interacción y permitieron apreciar las características específicas de la cultura política del mundo hispanoamericano. Así, según precisara Antonio Miguel Bernal, al igual que en el modernismo español, también desde el terreno de la historiografía política sobre los virreinatos indianos se ha cuestionado "el modelo coercitivo y centralizado de construcción y organización imperial", y puesto "en entredicho el paradigma de poder que trazaba una divisoria nítida entre opresores -centro, metrópoli- y oprimidos - periferia, colonia". ${ }^{2}$ Una de las consecuencias de esta hipótesis ha sido la incorporación -hace ya unos años- del concepto "pacto colonial" o más recientemente utilizar la categoría "imperio negociado". ${ }^{3}$ Ambos conceptos se han introducido para dar cuenta del proceso constante de negociación que tenía lugar entre y en los múltiples espacios de poder que jalonaban el camino entre la Corte madrileña y el ámbito local indiano. Hay, por lo tanto, un consenso que reconoce, tras la fachada aparentemente apolítica que en términos teóricos e institucionales presentaba la monarquía hispánica respecto de América, la existencia de una actividad política, fundamentalmente de carácter informal, que tenía

${ }^{1}$ Klein, "Finanzas", 1999, p. 13. Un interesante cuestionamiento a la lectura de Klein sobre la naturaleza del sistema fiscal colonial puede consultarse en Irigoin y Grafe, "Bargaining", 2008, pp. 173-209. Véase también la crítica a este artículo en Marichal, "Rethinking", 2008, pp. 211-218.

${ }^{2}$ Bernal, España, 2005, pp. 20-21.

${ }^{3}$ Véase Muro, "Reforma", 1982, pp. 47-68. Como señala atinadamente Bartolomé Yun, la idea de "imperio negociado" es menos innovadora de lo que se puede pensar ya que se encontraba presente en las obras de Lynch, Van Kleveren o Pietschmann. Se podrían añadir los trabajos de Zacarías Moutoukias o Margarita Suárez. Yun, "Introducción”, 2009, pp. 11-13. Puede consultarse también Daniels y Kennedy, Negotiated, 2002. 
lugar en distintas instancias, tanto centrales como locales, e incidía en la toma de decisiones y en su implementación en los virreinatos. Es decir, una dinámica que contemplaba formas de oposición, negociación, rectificación y acuerdo en el marco de una estructura difusa de poder, contrapuesta a la noción de que el poder político residía en un único centro. ${ }^{4}$

Posiblemente en ningún otro aspecto puedan considerarse con mayor claridad las características de la intensa vida política colonial, las dinámicas imperiales y la presencia del consenso entre el poder central y el ámbito local que en el terreno de la fiscalidad indiana. En este contexto historiográfico, el presente artículo se centra en el incremento de la presión fiscal en el virreinato de Perú durante la primera mitad del reinado de Felipe IV, concretamente entre 1621 y 1643. Es decir, coincidiendo con la preponderancia alcanzada por el valido real, el conde-duque de Olivares, en la Corte de Madrid. Este periodo se caracterizó por el énfasis excepcional demostrado por la corona en aumentar las remesas oficiales de plata procedentes de las Indias mediante la imposición de nuevas cargas fiscales -especialmente en Perú-, con el objetivo de afrontar los gastos bélicos crecientes de la monarquía.

Las décadas que nos ocupan poseen un gran interés, puesto que se trata de un tiempo en el que el mundo hispánico estaba experimentando la redefinición de las relaciones entre sus componentes y también una pérdida de su posición de poder en Europa. De hecho, fue durante el segundo cuarto del siglo XVII cuando comenzaron a ponerse de manifiesto los profundos cambios que venían gestándose desde hacía algunas décadas en varios espacios de la monarquía, y también cuando los territorios trasatlánticos adquirieron un papel más relevante en el mantenimiento del vínculo con la península. Entre otras cosas, conviene recordar que la posición de la corona y de la administración se debilitó cada vez más, tanto en Castilla como en las Indias, y que las relaciones trasatlánticas se vieron notablemente alteradas al mismo tiempo que la economía americana adquiría un carácter más maduro. También es importante tener presente el fortalecimiento de los grupos elitistas indianos y la pérdida del poderío exterior de la monarquía, tras los dilatados y sucesivos enfrentamientos mantenidos en el Nuevo y el Viejo Mundos. ${ }^{5}$

\footnotetext{
${ }^{4}$ Cañeque, "Cultura", 2001, p. 18.

${ }^{5}$ Para una aproximación a estos cambios en el mundo hispánico pueden consultarse, entre otros, Elliott, "América", 1971, y Conde, 2004; Andrien, "Sale", 1982, y Crisis, 1985; Assadourian, Sistema, 1982; Burkholder y Chandler, Impotencia, 1984; Moutoukias, Contrabando, 1988; Romano, Coyunturas, 1993, y Mecanismos, 2004; Israel, Razas, 1996; Ponce, Certezas, 1998; García, "Elites", 2000, pp. 89-110; Suárez, Desafios, 2001, p. 54; Oliva, "Pacto", 2003; Lynch, Historia, 2005, pp. 57-311; Garavaglia, Mercado, 2008, y Céspedes, América, 2009.
} 
A través del análisis de las cuentas de la Caja de Lima, este trabajo pretende demostrar que, aunque en el corto plazo el incremento de la presión fiscal se tradujo en el aumento de los ingresos y de las remesas oficiales de el Callao a Sevilla, en realidad se trató de un fenómeno transitorio que encubrió sólo de forma temporal la crisis fiscal que atravesaría el virreinato de Perú a lo largo del siglo XVII. Una crisis que no fue sino una de las tantas manifestaciones de la pérdida del control del poder central de la monarquía sobre los virreinatos americanos y que nos evidenciaría el carácter consensuado que iría adquiriendo el sistema fiscal indiano. En esta línea se busca poner de manifiesto que el aumento de los ingresos de la tesorería limeña y de las remesas de el Callao dependió estrechamente de la aquiescencia de los grupos de poder local, sobre todo respecto de las nuevas cargas introducidas entre 1627 y 1641, y del control de los gastos militares de la Caja de Lima por parte del virrey de Perú, el conde de Chinchón. Esta fiscalidad más exigente resultó especialmente efectiva en la capital virreinal, revelando una geografía de la capacidad de imposición de la administración, que entre otras cosas se manifestó en la reducción de la incidencia del rubro "venido de afuera" respecto de los ingresos generados en el distrito fiscal limeño.

\section{EL INCREMENTO DE LA PRESIÓN FISCAL EN LA AUDIENCIA DE LIMA}

El descenso de las remesas de plata procedentes del virreinato de Perú, advertido desde el comienzo del siglo XVII, fue un asunto que comenzó a inquietar a las altas instancias de la administración cortesana hacia la segunda mitad de la década de 1610. De hecho, luego de que las sumas remitidas desde el Callao se contrajeran abruptamente entre 1616 y 1619, Felipe III no sólo ordenó la averiguación de sus causas, sino que además sugirió la adopción de un conjunto de medidas que, en cierto modo, anticiparon algunas de las cargas fiscales impuestas durante el valimiento del conde-duque de Olivares. ${ }^{6}$ Pero no fue sino unos pocos años después cuando la cuestión comenzó a abordarse con más decisión: la caída del duque de Lerma y la muerte del monarca en 1621; el encumbramiento de una nueva facción cortesana -liderada por Baltasar de Zúñiga y el condeduque de Olivares- que procuró incrementar la capacidad del poder real; el estado cada vez más comprometido de la Real Hacienda y la reanudación de la guerra en el norte de Europa, modelaron una coyuntura que tuvo repercusión directa en la configuración de una política fiscal americana más agresiva. Desde comienzos del régimen de Olivares el poder

${ }^{6}$ Véase la real cédula del 13 de noviembre de 1620 en López, Noticia, 1989, t. 6, pp. 13-15. 
central de la monarquía concedió una gran relevancia a este asunto, y asumió un grado inusual de compromiso con el incremento de las remesas oficiales indianas. En la práctica, no se hizo esperar demasiado la decisión del enérgico régimen del principal ministro de Felipe IV de imponer a los territorios americanos -unas posesiones que en comparación con Castilla habían sido tratadas con bastante liviandad fiscal- nuevas contribuciones que se tradujeran en un aumento de su participación en la financiación de la política exterior de la monarquía.

La voracidad fiscal de los años del conde-duque de Olivares recayó fundamentalmente sobre el virreinato de Perú, y tuvo una expresión normativa que alcanzó prácticamente a la totalidad de los principales aspectos de la producción y el comercio coloniales. Salvo algunas excepciones, por lo general se trató de un conjunto de fórmulas carentes de originalidad. Lo más frecuente fue el recurso a medidas fiscales que ya habían sido propuestas o debatidas en el Consejo de Indias de años anteriores, a soluciones ensayadas previamente, o la intensificación de las ya existentes.

Pese a que la presión contributiva fue palpable durante los 22 años de predominio del valido -1621-1643-, el avance más significativo de Madrid sobre los súbditos americanos tuvo lugar a partir de los últimos años de la década de 1620, extendiéndose durante toda la década de 1630 y parte de la de 1640 . Es decir, que se concentró fundamentalmente en el virreinato de Luis Jerónimo Fernández de Cabrera y Bobadilla, conde de Chinchón, quien gestionó la implementación de las nuevas medidas fiscales hasta su regreso a España, en 1640. Su ascenso al solio virreinal coincidió con un momento decisivo del valimiento de Olivares desde el punto de vista económico. Fue precisamente aquí cuando se disiparon los tibios progresos que habían tenido algunos sectores de la economía castellana debido al aumento de las cargas de la Real Hacienda para financiar la guerra de Mantua, al incremento del precio del trigo y a la deflación que redujo las posibilidades de adquirir productos nacionales. ${ }^{7}$ A esto habría que añadir la captura del tesoro americano en la bahía de Matanzas por una flota comandada por Piet Heyn, que asestó un duro golpe a las finanzas de la monarquía y tuvo un fuerte efecto psicológico.

Entre las novedades fiscales del periodo que nos ocupa se destacan la Unión de Armas y los arbitrios del año 1631. Según se sabe, el primero fue uno de los proyectos más emblemáticos del conde-duque para los reinos de la monarquía. Sin embargo, si originalmente fue concebido como una contribución de soldados repartida proporcionalmente según la población y los recursos de cada una de las posesiones de Felipe IV, en los virreinatos indianos experimentó una profunda alteración y su puesta en vigor tuvo

${ }^{7}$ Elliott, Conde, 2004, p. 462. 
importantes retrasos. ${ }^{8}$ La contribución militar en la que tantas esperanzas tenía puestas Olivares se convirtió, a raíz de los cambios propuestos por el Consejo de Indias en 1627, en una nueva imposición fiscal que en Perú no comenzó a percibirse sino hasta la segunda mitad de la década de 1630 . La corona dispuso que el montante total de la Unión de Armas en los dos virreinatos ascendiera a 600000 ducados anuales repartidos de forma desigual; al virreinato de Perú, en razón de su mayor prosperidad, le correspondieron 350000 ducados, mientras que al de México se le encargó el aporte de los 250000 ducados restantes. Los 350000 debían repartirse entre todas las audiencias de Perú. Los virreyes y las autoridades de cada Audiencia dispusieron de un amplio margen de maniobra para introducir esta contribución, pues la orden para asentar la Unión de Armas estuvo acompañada de un conjunto de ocho arbitrios quienes debieron decidir cuáles eran los más apropiados respecto a las características y a la coyuntura del territorio de su jurisdicción. ${ }^{9}$ Por su parte, la contribución de la Unión de Armas en la Audiencia de Lima se situó en la alcabala, cuya tasa ascendió de 2 a 4\%, en la avería, que de 1 pasó a $2 \%$, y en el aumento del almojarifazgo sobre las botijas de vino. ${ }^{10} \mathrm{Si}$ en un primer momento fue establecida por quince años, lo cierto es que acabó adquiriendo un carácter permanente pese a que los ingresos que generó no alcanzaron -al menos durante los años del conde-duque Olivares- a cubrir las sumas asignadas.

Por su parte, los 19 arbitrios fiscales de 1631 fueron definidos tras un largo proceso deliberativo que implicó a múltiples instancias cortesanas, entre las que se encontraron el Consejo de Indias, varias juntas ad hoc y otra de teólogos. A lo largo de este proceso se pusieron de manifiesto las discrepancias sobre la extensión del avance fiscal entre un grupo de consejeros y el valido, quien procuró por varios medios conseguir el respaldo y la legitimación a un conjunto de arbitrios más agresivo. ${ }^{11}$ Las reales cédulas que finalmente se enviaron a Lima en 1633, por intermedio de un agente extraordinario, comprendieron la composición y venta de tierras baldías; la venta de los oficios de provinciales de la Hermandad, escribanías y alguacilazgos de corregimientos, receptorías de censos de los indios y su juzgado. También establecieron el pago de $2 \%$ de las cosechas de aquellas viñas que se hubieran plantado sin licencia real, el diezmo en el quintado

\footnotetext{
${ }^{8}$ Bronner, "Unión", 1967, pp. 1133-1176, y "Agente", 1975, pp. 29-62; Carta del fiscal de la Audiencia de Lima, Pedro Meneses, al Consejo de Indias, Lima, 20 de junio de 1639, en Archivo General de Indias (en adelante AGI), Lima, 164.

${ }^{9}$ Véase la real cédula sobre la imposición de la Unión de Armas y de los medios para asentarla, Madrid, 9 de abril de 1629, en AGI, Indiferente, 429, libro 37, fs. 117 y ss.

${ }^{10}$ Bronner, "Unión”, 1967.

${ }^{11}$ Véanse Amadori, "Privanza", 2008, pp. 63-84, y Bronner, "Tramitación”, 1981, pp. 411-441.
} 
de las joyas de oro y plata, la petición de un servicio gracioso en todo el reino, la incautación de plata de las cajas de comunidad, la prorrogación de una tercera vida en las encomiendas y situaciones de repartimiento de indios con cierta retribución, la composición de oficios renunciables anticipando la paga de la mitad o tercio, la concesión, previo pago, de títulos de villas y ciudades a los pueblos que las solicitaren, la venta de hidalguías, el establecimiento del estanco de pimienta en todo Perú, y, finalmente, el envío a España de todo el oro que se cobrase en las Cajas Reales. ${ }^{12}$

A las contribuciones referidas debe añadirse la introducción de la media anata en 1632. Como su nombre lo indica, consistía en el pago de media anualidad al que estaba obligada toda persona designada en un oficio o agraciada con una merced. ${ }^{13}$ Cabría mencionar, asimismo, las sisas que se colocaron sobre varios productos de consumo cotidiano, el beneficio y la venta de oficios, el pedido de varios donativos, o la promulgación de la Bula de la Santa Cruzada. Finalmente para completar el panorama, se debe atender a otros dos expedientes que aunque fueron aplicados por el sucesor del conde de Chinchón al frente del virreinato, el marqués de Mancera, han de ser incluidos en el incremento de la presión fiscal durante la década de 1630. Me refiero a las ventas de juros de 1639, 1640 y 1641, y a la introducción del impuesto del papel sellado en $1640 .^{14}$

Este amplio y heterogéneo programa fiscal también estuvo acompañado por el decidido esfuerzo de la corona de estrechar el control sobre la administración indiana, especialmente de la encargada del manejo de la Real Hacienda. Si bien no se produjeron modificaciones institucionales de gran relevancia, equiparables a las que a principios del siglo se habían traducido en la creación del Tribunal de Cuentas de Lima, sí se puso especial énfasis en reiterar incansablemente el encargo -prácticamente a la totalidad de las autoridades indianas- de cumplir y hacer cumplir las cédulas con fines controladores que habían sido despachadas con anterioridad. Los temas que más aparecen en las órdenes reales son la fiscalización del comercio trasatlántico, el cobro de las deudas de la Real Hacienda, el quintado y el ensaye de los metales preciosos, la persecución del contrabando intercolonial y de todo tipo de fraude fiscal, el correcto manejo de la Hacienda del rey, los límites del poder de los virreyes y el comportamiento privado de los servidores reales. Asimismo, en estos años se dio la proliferación de las visitas, que se convirtieron en una práctica

\footnotetext{
${ }^{12}$ El texto de las cédulas se puede consultar en AGI, Indiferente, 429, libro 37, fs. 227-252.

${ }^{13}$ Un estudio jurídico pormenorizado del derecho de media anata puede consultarse en Rodríguez, "Derecho", 1986, pp. 455-464.

${ }^{14}$ Andrien, "Sale", 1981, pp. 1-19, y Martínez, "Sala", 1986, pp. 455-464.
} 
de averiguación sumamente frecuente que alcanzó a buena parte de las instituciones americanas. ${ }^{15}$

En la capital virreinal, la imposición de la Unión de Armas y el establecimiento de los arbitrios de 1631 tuvieron lugar de forma simultánea a lo largo de la década de 1630. De hecho, estas nuevas cargas estuvieron precedidas de un complicado proceso de negociación, de varios años de duración, en el que se buscó la aquiescencia de los grupos de poder local, que plantaron una resistencia canalizada fundamentalmente a través del Cabildo limeño. Esta circunstancia acabó condicionando el resultado del programa fiscal que experimentó algunas variaciones importantes respecto de las disposiciones que habían sido enviadas desde Madrid. Por su parte, a lo largo de la imposición de estas cargas la corona pudo considerar cómo mermaba su capacidad de controlar un proceso fiscal cuya gestión quedó a cargo del virrey que se desempeñó con gran autonomía. El conde de Chinchón disfrutó de un importante margen de maniobra y, en la práctica, actuó como un intermediario entre la corona y la elite limeña. ${ }^{16}$ Incluso, en ciertas ocasiones se alineó decididamente con las reclamaciones de esta última. Por ejemplo, no sólo secundó varias alternativas para incrementar institucionalmente el poder de las elites indianas, sino que su pensamiento político tenía un elemento central que no estaba en sintonía con las urgencias del régimen del valido: su convencimiento de la necesidad, o al menos la conveniencia, de establecer una forma de representación que les permitiera a los cuerpos políticos de la monarquía manifestar la aceptación -e incluso eventualmente el rechazo- de las cargas fiscales. ${ }^{17}$

En esta línea, varios de los 19 arbitrios de 1631 se desecharon y se evitó avanzar sobre ciertos sectores concretos, como los encomenderos. Sin embargo, no se debe soslayar que el programa enviado desde Madrid en ciertos aspectos resultó atrayente para los intereses de una parte de la elite local, ya que le permitió incrementar su participación en el ejercicio del poder, sobre todo en lo que respecta a la venta de cargos. Hay que tener presente que durante la primera mitad del siglo XVII los grupos de poder americanos estaban consolidando su posición en el espacio local, procurando obtener riquezas, puestos en la administración y, en menor medida, el reconocimiento de los privilegios de sus linajes. Frente a la afirmación elitista, el gobierno central de la monarquía se vio obligado a contar cada vez más con su colaboración para poder movilizar los recursos

${ }^{15}$ Como ejemplos pueden consultarse Israel, Razas, 1996, y Phelan, Reino, 1995.

${ }^{16}$ Para la negociación del virrey Chinchón con los grupos de poder local, véase Amadori, Política, 2011, cap. 4 .

${ }^{17}$ Véanse Copia de la carta del conde de Chinchón a Felipe IV, Madrid, 14 de marzo de 1628, y Carta del conde de Chinchón a Felipe IV, Lima, 31 de marzo de 1633, en AGI, Indiferente, 2690 . 
americanos, mantener elevadas las remesas reales y asegurar la gobernabilidad de los virreinatos. ${ }^{18}$

En definitiva, la década de 1630 posee un gran interés desde el punto de vista fiscal, puesto que no sólo representa el intento más importante del siglo XVII de aumentar las cargas a las que estaba sometido el virreinato de Perú, sino también porque revela las características funcionales del régimen del conde-duque de Olivares en varios espacios de poder, las dinámicas administrativas propias de la gestión colonial y los cambios en los ramos fiscales de la Caja de Lima.

\section{LOS RESUltados de la PRESIÓn Fiscal a TRAVÉS DE LA CAJA DE LiMA}

En términos absolutos, resulta muy claro que el aumento de la presión fiscal se tradujo en un incremento sostenido de las remesas oficiales enviadas desde el Callao a España y de los ingresos de la Caja de Lima. ${ }^{19}$ Sin embargo, lo cierto es que cada uno de estos dos apartados presentó un ritmo propio que reclama una explicación particular. ${ }^{20} \mathrm{El}$ hecho de que hayamos centrado nuestro análisis en la Caja de la ciudad de los Reyes responde

${ }^{18}$ Amadori, "Mayor", en prensa.

${ }^{19}$ Para la organización y el funcionamiento de la Caja de Lima existen dos obras contemporáneas imprescindibles, véanse Escalona, Gazophilacium, 1775, y López, Noticia, 1989, t. v, especialmente el libro IV, discurso XXIX. Véase también Recopilación, 1681, libro VIII. Otro texto fundamental, aunque dedicado a la Hacienda novohispana, es el de Maniau, Compendio, 1995.

${ }^{20} \mathrm{El}$ análisis que proponemos se apoya en los sumarios recopilados por TePaske y Klein para la Caja de Lima (TePaske y Klein, Royal, 1982, t. I), en la reelaboración que Andrien realizó de estos datos a la luz de otras series documentales virreinales (Andrien, Crisis, 1985), y en las cartas cuenta de las remesas trasatlánticas publicadas por Báncora, "Remesas", 1959, y Rodríguez, "Caudales", 1964. Desde su publicación, los sumarios de TePaske y Klein han dado lugar a un intenso debate. Indudablemente, el eje de las críticas fue la cuestión de su pertinencia para indicar tendencias económicas. Las limitaciones que se les han señalado son de diversa naturaleza y apuntan, entre otras cosas, a los procedimientos contables de la época, a la corrupción o a la incidencia de una sociedad de antiguo régimen, conformada por individuos de diversa condición jurídica y fiscal, en los registros. Puede verse una rápida revista de algunos de los problemas en Kamen e Israel, "Seventeenth", 1982, pp. 144-156; Klein, Finanzas, 1994, cap. I, y en la introducción de Slicher, Real, 1989. Resulta esencial la consulta del trabajo de Pérez, "Beneficiarios", 1991. Apuntes sobre el caso concreto peruano, véanse en Suárez, "Perú”, 2009, pp. 254 y ss. El artículo de Klein y Barbier, "Recent", 1988, resulta muy esclarecedor del debate suscitado en torno a los sumarios. Debido a la lectura política de la fiscalidad que proponemos aquí, de los ramos en los que nos hemos centrado, y del complemento que suponen las cartas cuentas de Báncora y, sobre todo, los datos de Kenneth a los sumarios, que esclarecen la transferencia entre las Cajas virreinales, entendemos que el apoyo documental utilizado resulta adecuado para los fines de esta investigación. Existe, sin embargo, un aspecto en el que un análisis contable detallado de los resúmenes de cuentas hacendísticas podría profundizar en las conclusiones alcanzadas aquí. Me refiero a la incidencia de los préstamos en el funcionamiento ordinario de la Caja de Lima, ya que muchas veces la toma de dinero se registraba intencionadamente en otros ramos para ocultar el endeudamiento. Sobre esta problemática véase Suárez, Desafíos, 2001, p. 267. 
al papel esencial que desempeñaba en el andamiaje administrativo colonial. En la práctica, los resúmenes de cuenta de este organismo pueden considerarse como un indicador de las tendencias fiscales generales de buena parte del espacio virreinal, puesto que estaba encargado de recibir los excedentes de las tesorerías del Alto y Bajo Perú y de redistribuir las sumas ingresadas. De modo que era precisamente en Lima donde se decidía cuánto se retenía para los gastos locales, cuánto se remitía en concepto de situados y cuánto se enviaba a España. ${ }^{21}$

\section{Los "nuevos" ingresos}

Las entradas de la Caja de Lima experimentaron un aumento constante entre 1625 y 1655 , de carácter más leve que el de las remesas oficiales a Castilla, que sirvió para colocar los ingresos en valores superiores a los alcanzados hasta 1610 (véase gráfica 1). Ahora bien, ¿cómo se componían estos ingresos?, ¿cómo se explica su movimiento en un marco configurado por los primeros compases de una crisis fiscal y por el aumento de la presión de la corona?

Antes de continuar con la descripción de los ingresos es fundamental realizar dos aclaraciones. En primer lugar, debido a que nuestro análisis se centra en la composición de los ingresos y los gastos y en la variación de los ramos que los componían, hemos preferido expresar las cifras en valores corrientes, es decir, en pesos de ocho reales, en lugar de hacerlo en valores constantes deflactados. De cualquier modo, la incidencia de la inflación en el periodo comprendido entre 1625 y 1645 no invalida las afirmaciones pertinentes al aumento absoluto de los ingresos y de las remesas. ${ }^{22}$ En segundo lugar, resulta pertinente introducir otra aclaración relativa a la lógica interna de la Real Hacienda en el antiguo régimen. Para realizar una lectura política de la fiscalidad que permita reconstruir las bases financieras de la corona y sus eventuales cambios, es esencial interpretar su organización, precisar la naturaleza de cada ramo contable y, sobre todo, tener presente que entre los ingresos y los gastos existía una relación peculiar distinta de la que tenía lugar en la Hacienda liberal. De hecho, en la estructura contable virreinal los ramos del cargo estaban vinculados a ramos de la data, con lo cual no tenía las mismas consecuencias políticas que el aumento o la disminución de un ingreso se produjera en los ramos ordinarios o en los extraordinarios, ni que la variación se experimentara

\footnotetext{
${ }^{21}$ Suárez, Desafios, 2001, p. 54.

${ }^{22}$ Noejovich, "Nivel", 2006, pp. 379-380. Sobre los precios en Perú puede consultarse el monumental trabajo de Macera, Precios, 1992.
} 

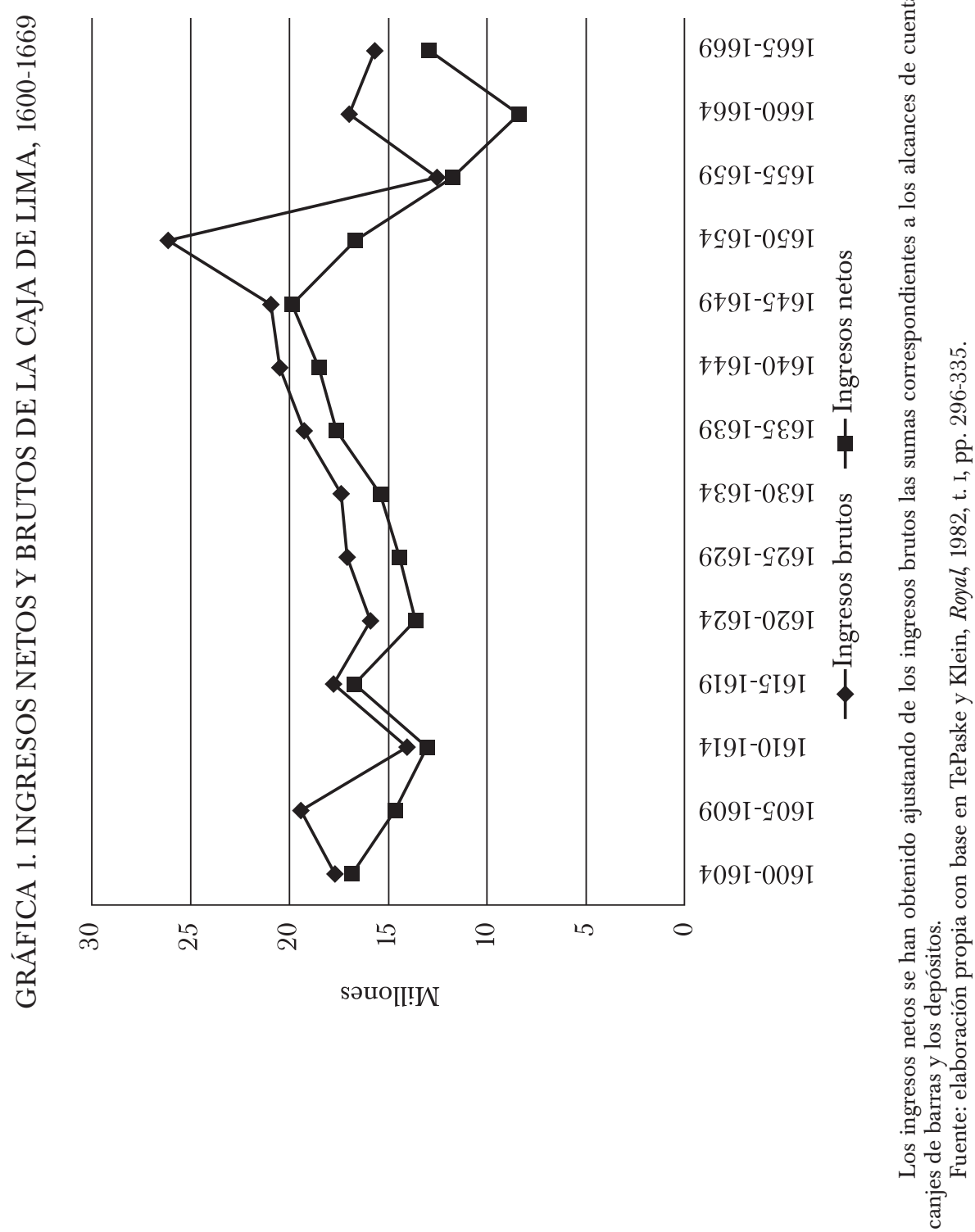
en los ingresos brutos o en los netos. ${ }^{23}$ Dicho esto, es importante atender el hecho de que la organización de la Real Hacienda se fue perfeccionando y haciendo más puntillosa según avanzaba el régimen colonial. Estos cambios no sólo afectaron el registro de los ramos, cuyo número aumentó notablemente con el correr del tiempo, sino también la disciplina administrativa. En este sentido, resulta fácil advertir la distancia que separa la obra del contador López de Caravantes ( $c a .1640)$ de la de Joaquín Maniau (1792). Frente a la meticulosidad de este autor que se mueve en el ámbito de la teoría, el tratado de Caravantes revela unas pautas de funcionamiento mucho más laxas, que no sólo ponen de manifiesto el incumplimiento de la legislación y unos márgenes muy amplios de improvisación, sino que incluso recuerdan la lógica de la Hacienda liberal. ${ }^{24}$

Según hemos explicado, las décadas de 1620 y 1630 consideraron la mayor avanzada fiscal que Madrid lanzó sobre los virreinatos trasatlánticos en todo el siglo XVII. Pero una aproximación a las cuentas limeñas revela que las innovaciones impositivas tuvieron una incidencia cuantitativa limitada, que guardó poca concordancia con el pulso político que las precedió y, en definitiva, las condicionó.

En la Caja de Lima, como en el resto de las Cajas Reales indianas, la contabilidad de los ingresos y los egresos se realizaba a partir de decenas de ramos fiscales. No obstante, en la capital virreinal muy pocos de estos apartados completaban prácticamente la totalidad de las entradas. Es decir, que sólo un número muy corto de ellos poseía relevancia cuantitativa. Entre ellos ocupaba un lugar central el ramo "venido de afuera", correspondiente a las remesas de los distritos mineros y de aquellos con numerosa población indígena, los cuales generaban excedentes fiscales que se enviaban a Lima. Fundamentalmente destacaban los enviados de Potosí, que se complementaban con los de Oruro, Cailloma, La Paz, Cuzco, Arequipa o San Antonio de Esquilache. ${ }^{25}$

Desde comienzos del siglo XVII hasta finales de la década de 1630, en Lima se habían recibido importantes sumas procedentes de las Cajas subordinadas que ascienden a casi 14000000 de pesos de ocho reales en el quinquenio 1635-1639. En cambio, durante las décadas de 1640 y 1650 se produjo un descenso que sólo se revirtió temporalmente en el quinquenio 1650-1654. A partir de este año, se produjo una caída muy pronunciada que se extendió a lo largo de una década. Esta circunstancia reflejó la

${ }^{23}$ Para una descripción de la organización de los ramos véase Pérez, "Beneficiarios", 1991, pp. 222 y ss. Para una explicación pormenorizada pueden consultarse las obras de dos tratadistas de la Real Hacienda colonial, Escalona, Gazophilacium, 1775, libro II, parte II, y López, Noticia, 1989, t. VI, libro IV, especialmente el discurso XXIII, y Maniau, Compendio, 1995, partes I y II.

${ }^{24}$ Véase López, Noticia, 1989, t. vI.

${ }^{25}$ Andrien, Crisis, 1985, p. 62. 
retracción de los envíos procedentes de Potosí, Oruro y Cailloma, que no fueron compensados con el incremento de las remesas de otras Cajas como La Paz o San Antonio. La contracción del rubro "venido de afuera" tenía profundas consecuencias no sólo por su aporte porcentual a los ingresos de la Caja de Lima, sino también porque componía la parte principal de las remesas a Castilla (véase gráfica 2). De hecho, las partidas de los principales distritos mineros debían enviarse directamente a España, no pudiéndose aplicar para gastos locales. Sin embargo, como recuerda el contador Caravantes, se trató de una disposición que difícilmente pudo cumplirse durante los años que nos ocupan.

Desde finales de la década de 1630, los ingresos netos totales por quinquenios no sólo no se contrajeron al ritmo del descenso del ramo "venido de afuera", sino que incluso se incrementaron levemente. La razón está en el aumento de un conjunto de rubros fiscales, muchos de los cuales reflejaron claramente el carácter de la fiscalidad del periodo del condeduque de Olivares, concretamente las nuevas imposiciones y los recursos contributivos que se establecieron -en su mayoría- durante el virreinato del conde de Chinchón, pero que alcanzaron toda su incidencia en el de su sucesor, el marqués de Mancera, y conservaron cierta vigencia. Como consecuencia, a diferencia de lo que había ocurrido antes y como sucedería después, entre 1639 y 1655, los ingresos netos totales de la Caja de Lima dejaron de tener una dependencia tan estrecha del ramo "venido de afuera" (véase gráfica 2).

En los años que analizamos se contabilizan importantes sumas percibidas dentro de los siguientes rubros: ventas y composiciones de tierras, Unión de Armas, media anata, venta y renunciación de oficios, papel sellado, censos, donativos, Bula de la Santa Cruzada, mesada eclesiástica, extraordinario y tributos vacos. Detengámonos, en primer lugar, en los ingresos ordinarios generados por los rubros que se crearon durante el valimiento del conde-duque de Olivares, pero que continuaron vigentes por varias décadas. Aquí debemos ubicar -en orden decreciente según su rendimiento- a la Unión de Armas, la media anata y el papel sellado. Según señala el tratadista Escalona y Agüero, todos estos apartados tenían la particularidad de haber sido establecidos con la finalidad explícita de remitirse a España por cuenta aparte. ${ }^{26}$ También entre los ramos ordinarios hay que señalar el sensible incremento de los tributos vacos durante el quinquenio 1640-1645.

${ }^{26}$ Véase Escalona, Gazophilacium, 1775, partes I y II, libro II. 
GRÁFICA 2. INGRESOS NETOS, VENIDO DE AFUERA Y REMESAS A CASTILLA DE LA CAJA DE LIMA, 1600-1669

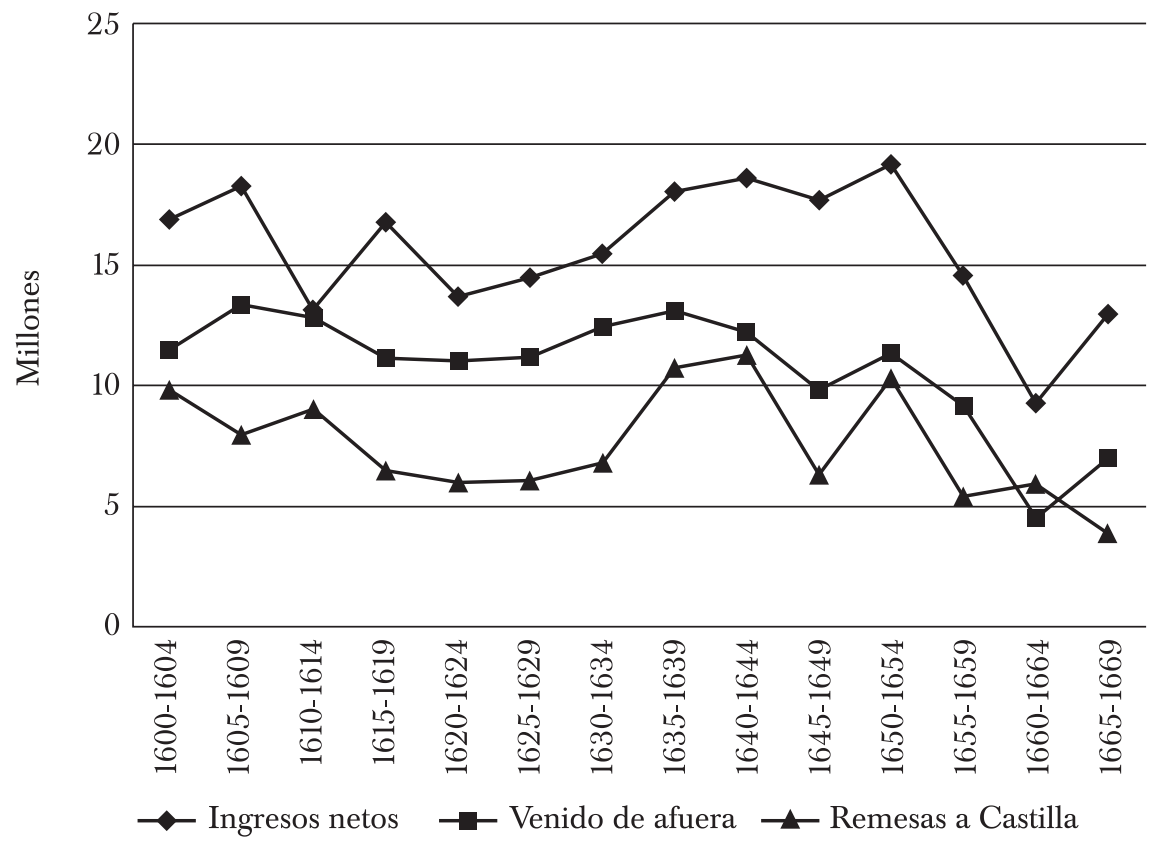

Fuente: elaboración propia con base en TePaske y Klein, Royal, 1982, t. I, pp. 296-335.

Por su parte, otro de los apartados introducidos en estos años fue el estanco de la nieve y la aloja, que formaba parte de los rubros especiales. ${ }^{27}$ Las sumas ingresadas por este concepto se enviaban a la península para sufragar los gastos del Palacio del Buen Retiro de Madrid. La Bula de la Santa Cruzada y la mesada eclesiástica -ramo que se creó hacia finales de la década de 1620 - percibieron sumas que en conjunto rondaron 5\% de los ingresos netos. Ambos apartados correspondían a la categoría particular, puesto que estaban destinados a sufragar gastos eclesiásticos. ${ }^{28} \mathrm{De}$ todos modos, la corona dispuso que el producto de estos ramos se enviara a España por cuenta aparte. ${ }^{29}$

\footnotetext{
${ }^{27}$ Los rubros especiales estaban compuestos por los estancos, como el tabaco, los naipes y el azogue, y su producto era remitido directamente a España. Pérez, "Beneficiarios", 1991, p. 222.

${ }_{28}^{28}$ Ibid.

${ }^{29}$ Escalona, Gazophilacium, 1775, pp. 243 y ss.
} 
A pesar de que algunos de estos medios ordinarios generaron ingresos muy significativos, los rendimientos fiscales alcanzados entre 1630 y 1650 no se explican sin los mecanismos extraordinarios que se impulsaron desde Madrid y que le dieron a la fiscalidad de la época un carácter peculiar. En este sentido, los ingresos de naturaleza financiera tuvieron un papel muy importante. Entre 1640 y 1655, el porcentaje correspondiente a los censos respecto de los ingresos netos totales osciló entre 1.6 y 3.5\%, alcanzando cierto impacto por primera vez en la centuria. En cualquier caso, se trató de un incremento de carácter transitorio y unos límites muy concretos, puesto que en el largo plazo aumentaban los egresos de la Real Hacienda, tal como ocurrió en la década de 1640. Durante este periodo, la suma destinada a la satisfacción de préstamos pasó de los 20000 ducados hasta superar los $90000 .^{30}$ Por su parte, los servicios graciosos también aportaron cantidades considerables, aunque afectaron las relaciones políticas de la elite local con la corona. Así, por ejemplo, en los quinquenios 1621-1625, $1635-1639$ y $1640-1645$, alcanzaron 1.6, 2.7 y $1.8 \%$ de los ingresos netos totales, respectivamente. Algo más importante fueron las renunciaciones y las ventas de oficios.

Una incidencia mucho más destacada tuvieron las composiciones, especialmente las de tierras. Mientras que las correspondientes a las pulperías nunca alcanzaron $0.5 \%$ de los ingresos, las ventas y composiciones de tierras llegaron a representar $6.3 \%$ de los ingresos netos en la década de 1640 (véase cuadro 1).

Finalmente, el rubro extraordinarios de Real Hacienda participó con 5.5 y $5.9 \%$ durante las décadas de 1630 y 1640. Se trataba de un ramo de bastante magnitud que, como indica su propia denominación, se utilizaba para registrar aquellos ingresos para los que no había una categoría específica. Por lo tanto, incluía sumas de diversa procedencia, aunque era frecuente que consignara el dinero generado por las ventas de azogue, madera para la construcción naval, licencias, o lo remitido en concepto de extraordinario desde Cuzco, La Paz u Oruro. ${ }^{31}$ Como su nombre y su montante indican, se trataba de un ingreso de carácter irregular que, sin embargo, fue incrementando su importancia a medida que avanzaba la centuria. Así, en el quinquenio 1665-1669 llegó a representar 20\% de los ingresos netos. A diferencia de los rubros ordinarios, su destino no estaba claramente definido, aunque parece claro que, al menos durante la segunda parte del valimiento de Olivares, buena parte de ellos se aplicaron a las remesas a Castilla.

\footnotetext{
${ }^{30}$ Andrien, "Sale", 1981, p. 15.

${ }^{31}$ TePaske y Klein, Royal, 1982, t. I, p. XIV.
} 


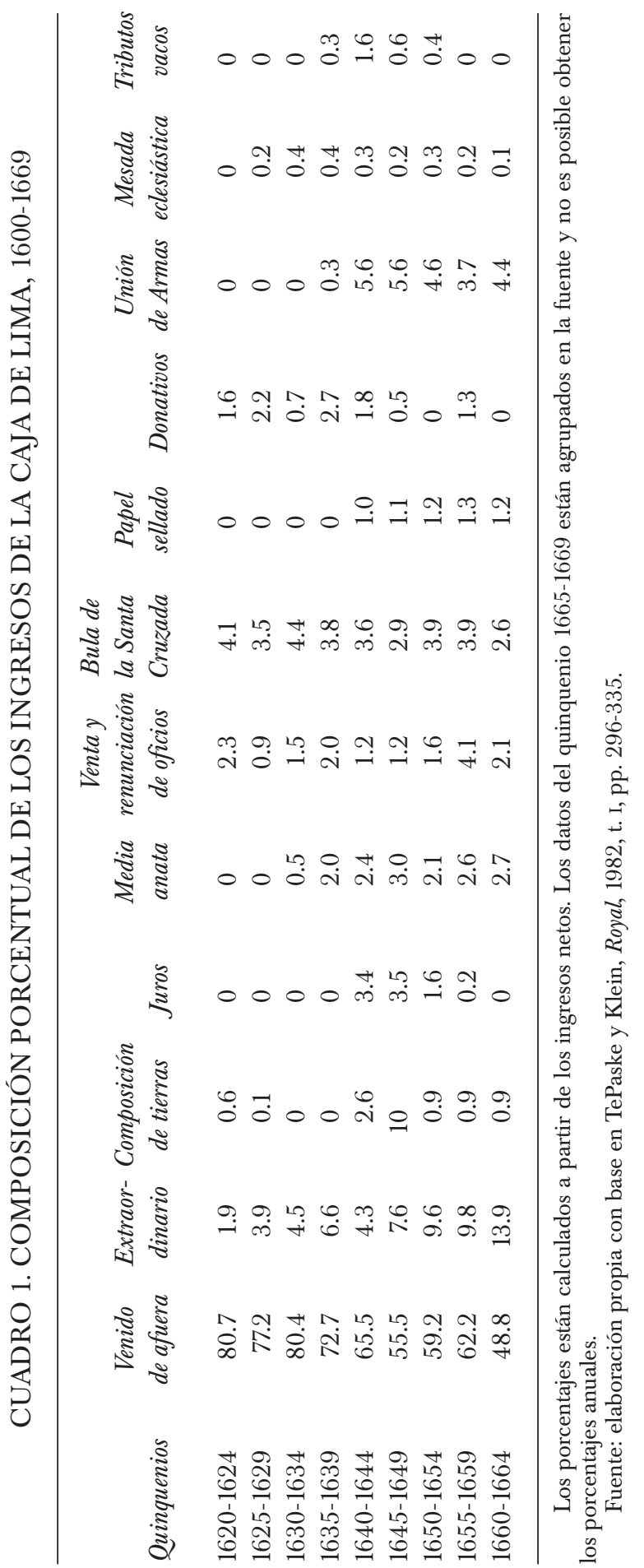


Insistiendo en el aumento de la presión fiscal, es fundamental reparar en el hecho de que estos "nuevos" ingresos correspondieron exclusivamente a la Caja de Lima. Si a las entradas totales de esta caja se resta el rubro "venido de afuera" se constata que el incremento de los ingresos -fiscales y financieros- de este distrito fue realmente muy importante a partir de 1640 (véase gráfica 3), es decir, cuando se consolidaron las cargas y las prácticas introducidas durante los años del conde de Chinchón. Puesto que en la jurisdicción limeña ni los quintos reales ni los tributos indígenas eran relevantes, el aumento de los ingresos provino especialmente de la actividad comercial, la administración y la Iglesia. Esta última participó, sobre todo, a través de los mecanismos financieros. ${ }^{32}$

Pese a que el apartado extraordinario aumentó sensiblemente su participación en los ingresos de la Tesorería de Lima, los préstamos tuvieron una evolución que no correspondió con las urgencias europeas de la monarquía. De hecho, en el segundo quinquenio del valimiento del condeduque de Olivares (1625-1629) los préstamos prácticamente alcanzaron los 2500000 pesos de ocho, lo que representó 14\% de los ingresos brutos. Sin embargo, en los cuatro decenios subsiguientes descendieron abruptamente, al punto de que entre 1635 y 1639 se situaron en 6\%, una cifra semejante a la alcanzada durante las dos primeras décadas del siglo XVII.

Con carácter general, una de las principales diferencias entre la fiscalidad colonial y la peninsular consistió en el tándem conformado por la disponibilidad de trabajo indígena y la riqueza de los enclaves mineros en América. ${ }^{33}$ De hecho, como refleja lo "venido de afuera" de la Caja de Lima, el rubro de mayor impacto en la fiscalidad peruana era el que correspondía a los quintos de los metales preciosos, especialmente la plata. Esta circunstancia sugiere detenerse -aunque sea brevemente- a considerar la evolución de la producción argentífera en el virreinato para intentar caracterizar el impacto de la fiscalidad promovida por el conde-duque de Olivares.

La producción de plata en el virreinato de Perú a lo largo del siglo XVII es un tema que ha ocupado un lugar central en la historiografía económica americanista. Junto al comportamiento de las remesas oficiales a Castilla -a las que está vinculado- y el volumen del comercio atlántico, las cifras estimadas de la minería argentífera han sido tenidas por mucho tiempo como uno de los indicadores de una crisis que habría afectado por igual a la economía española y a la americana. ${ }^{34}$ Indudablemente, el lugar central de las investigaciones lo ha ocupado el cerro de Potosí que, como afirma

\footnotetext{
32 Noejovich, "Economía", 1997, p. 331.

${ }^{33}$ Irigoin y Grafe, "Bargaining", 2008, p. 183.

${ }^{34}$ Suárez, "Crisis", 2000, p. 296.
} 
GRÁFICA 3. INGRESOS DE LA CAJA DE LIMA

EXCEPTUANDO EL RUBRO VENIDO DE AFUERA, 1600-1669

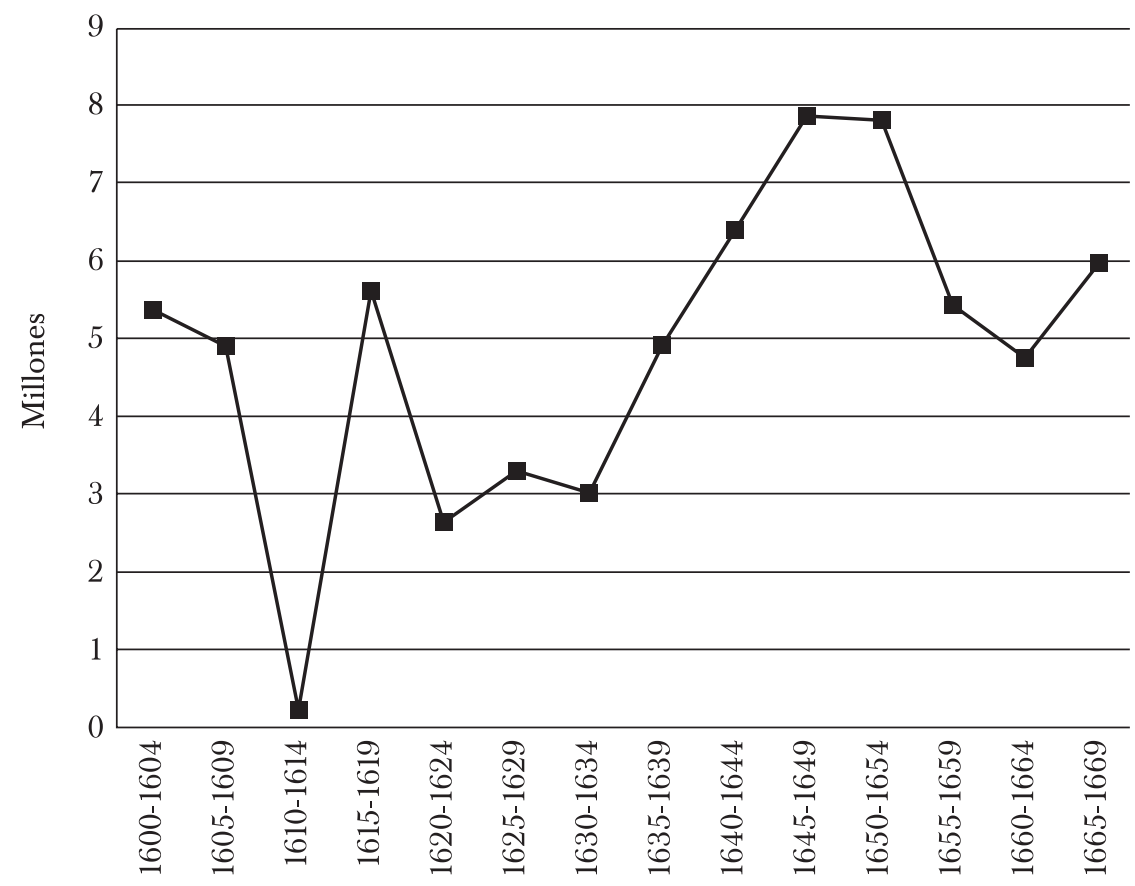

Fuente: elaboración propia con base en TePaske y Klein, Royal, 1982, t. I, pp. 296-335.

Romano, se ha utilizado con frecuencia para explicar las contingencias de la minería de plata en todo el virreinato. ${ }^{35}$ La producción de este enclave ocupó un sitio preponderante en la minería peruana, al punto de que entre 1570 y 1630 se extrajo del cerro entre 80 y $85 \%$ de toda la plata obtenida en el virreinato. ${ }^{36}$ Sin embargo, desde comienzos del siglo XVII el centro comenzó a mostrar una retracción en los quintos, que presentaron un ritmo variable a lo largo de la centuria. Hasta el último cuarto de siglo, el descenso, aunque interrumpido ocasionalmente, fue lento pero con una tendencia marcada. Paradójicamente podrían destacarse algunos incrementos notables en la recaudación, como los ocurridos en 1635 y 1646. Estos repuntes traducirían, más que un aumento de la producción,

\footnotetext{
${ }^{35}$ Romano, Coyunturas, 1993, pp. 91-92.

${ }^{36}$ Fisher, "Producción", 2000, pp. 139.
} 
un incremento de la presión fiscal. Pero en los años finales de la centuria la contracción alcanzó un ritmo muy acusado que no se detuvo hasta la segunda década del siglo XVIII. ${ }^{37}$ Aparentemente la caída de la producción no fue tan abrupta como proponen los datos fiscales, por lo cual algunos autores muestran una total desconfianza acerca de su pertinencia para fundamentar una tendencia general de la producción argentífera. ${ }^{38}$

En este contexto, existen varios factores que relativizan la envergadura de la caída de la producción potosina. En primer lugar, la dispersión experimentada por la minería de plata desde comienzos del siglo XVII, al incorporarse algunos centros menores que contribuyeron a equilibrar la producción total del virreinato. ${ }^{39}$ En segundo lugar, un dato interesante es el cálculo que elaboraron hace ya muchos años Brading y Cross sobre el consumo de azogue en el virreinato de Perú. Pese a que los indicadores generales de la productividad, basados en la recaudación fiscal, muestran una baja constante desde 1600 hasta la mitad del siglo, estos autores sugieren, a partir del múltiplo entre el rendimiento mínimo por quintal de azogue y el total de quintales consumidos, que el pico máximo de la producción de plata fue alcanzado entre 1625 y $1640 .{ }^{40}$ Además, la gráfica que proponen revela que, aunque se produjo un descenso en el consumo de azogue hacia la década de 1660, luego tuvo lugar un repunte que alcanzó niveles semejantes a los de los primeros años de la centuria. Posteriormente se produjo una caída abrupta del consumo que se extendió desde 1675 hasta fines de la década de 1680, para luego comenzar a recuperarse antes de finales del siglo. ${ }^{41}$ De modo que se constata una base productiva mínima bastante fiable -susceptible de ser incrementada sustancialmente con la añadidura de la plata obtenida mediante otros métodos- y se refuerza aún más la revisión de una hipotética crisis general de la minería de plata durante el siglo XVII. En este sentido, no conviene perder de vista la existencia de un mercado negro de azogue.

En tercer lugar, existe otro indicador que contribuye a trasladar el problema de la caída de los quintos reales del terreno económico al terreno fiscal: el volumen de la exportación de plata obtenido por Morineau.

${ }^{37}$ Bakewell, "Registered", 1975, pp. 85-86, y "Minería”, 2000, pp. 83-84.

${ }^{38}$ Romano, Mecanismos, 2004, pp. 137 y 141. Este autor cita los testimonios de Nicolás de Martínez Arzans y Vela y de Humboldt para resaltar la envergadura de la evasión fiscal, a pesar de que aclara que no pueden ser tomados como indicadores fiables. El primero, por ejemplo, calculaba que desde 1645 la mitad de la plata extraída en Potosí no había pagado el quinto correspondiente, ya que se extraía de forma clandestina por el puerto de Buenos Aires. Para Noejovich, "estamos frente a una economía paralela que tenía una actividad casi aproximada a la economía oficial". Véase Noejovich, "Caudales", 2001, p. 297.

${ }^{39}$ Romano, Coyunturas, 1993, pp. 91-92.

${ }^{40}$ Brading y Cross, "Colonial”, 1972, pp. 572, 576, 579.

${ }^{41}$ Ibid., p. 572. 
Según sus cálculos, durante toda esta centuria se recibió en Europa un total de 158 toneladas de oro y 26168 de plata. ${ }^{42}$ En cuanto a la tendencia general, los envíos argentíferos revelados por este investigador muestran para la segunda mitad del siglo XVII cifras comparables, e incluso superiores, a las de finales del siglo anterior. ${ }^{43} \mathrm{~A}$ esta circunstancia habría que agregar que, para los años que nos ocupan, más de $20 \%$ de la plata obtenida en Potosí era exportada por la ruta ilegal que tenía como cabecera el puerto de Buenos Aires. ${ }^{44}$

En definitiva, parece claro que a pesar de que no se pueda determinar con precisión el volumen de la producción argentífera, todos estos indicios cuestionan los datos oficiales e inducen a replantear la consagrada versión de la decadencia de la minería en la segunda mitad del siglo XVII. Con lo cual, parecería más pertinente plantear el problema de un modo distinto, no concentrándose solamente en el ámbito económico sino más bien incluyendo la dimensión política de la fiscalidad.

\section{Las remesas a Castilla}

Hasta aquí hemos visto cuál fue la situación de los ingresos. A diferencia de estos, las remesas a Castilla mostraron una clara ruptura con la tendencia decreciente que habían experimentado desde los primeros años del siglo XVII. Tal como se aprecia en la gráfica 1, a comienzos de la centuria se había alcanzado la cantidad de 2500000 pesos de ocho reales anuales, mientras que en 1620 y 1621 se situó en un punto mínimo en el que rondó los 600000 pesos. A partir de entonces se verificó un alza muy marcada hasta mediados de la década de 1640. En términos corrientes, este aumento llevó las remesas a los niveles semejantes a los alcanzados a fines del siglo XVI. En 1642, por ejemplo, las remesas oficiales a Castilla se situaron por encima de los 2500000 pesos de ocho, marcando el máximo de la primera mitad de la centuria (véase gráfica 2).

La disparidad entre la intensidad del incremento de las remesas y la de los ingresos de la Caja de Lima nos sitúa frente a una de las claves de la fiscalidad peruana de los años del conde-duque de Olivares (véase gráfica 4). La explicación a este fenómeno se debe ubicar tanto en el aumento de la presión fiscal, como en la asignación de los gastos de la Real Hacienda

\footnotetext{
${ }^{42}$ Romano, Mecanismos, 2004, p. 143.

${ }^{43}$ Romano, Coyunturas, 1993, p. 90, y Mecanismos, 2004, p. 142, y Morineau, Incroyables, 1985, p. 563.

${ }^{44}$ Moutoukias, Contrabando, 1988, p. 16.
} 


\section{GRÁFICA 4. VARIACIÓN PORCENTUAL DE LAS REMESAS A CASTILLA Y DE LOS INGRESOS DE LA CAJA DE LIMA, 1600-1669}

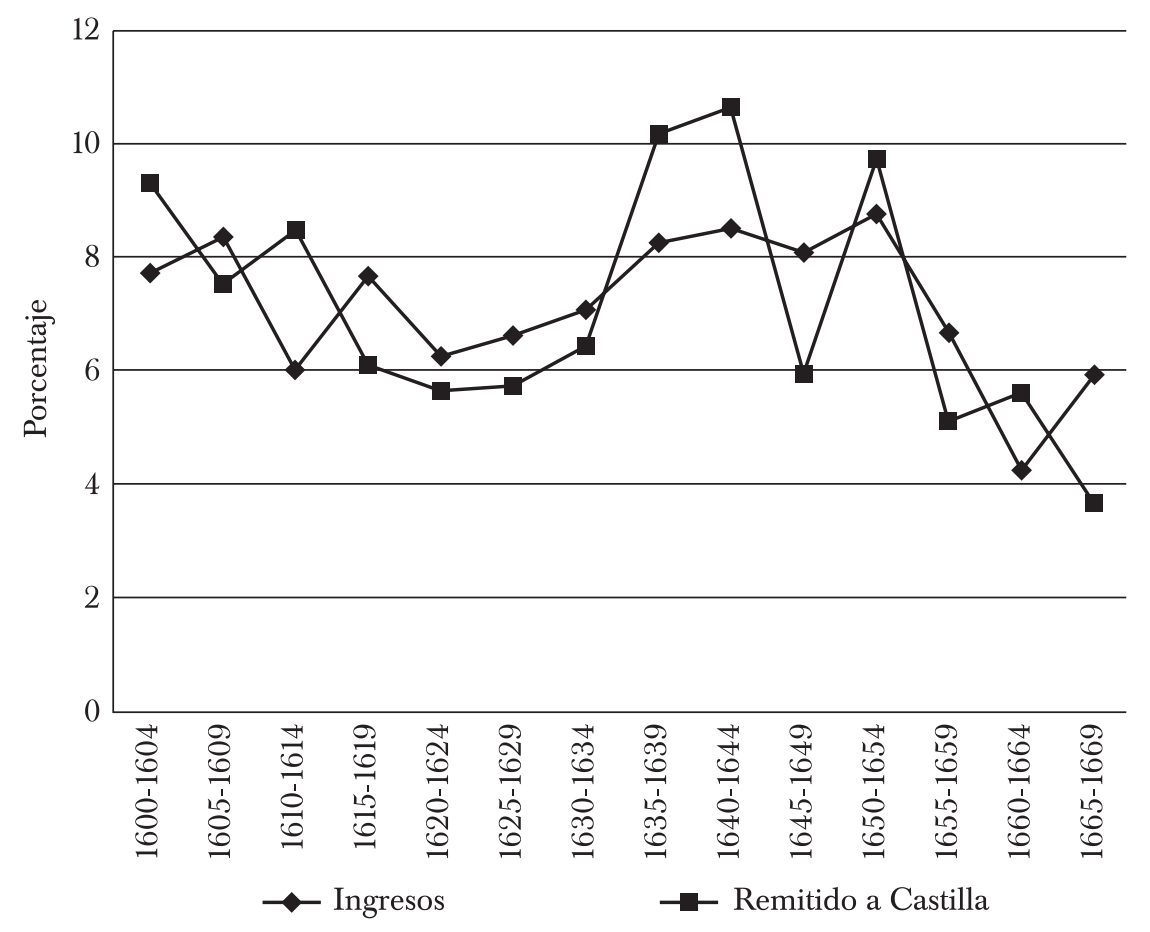

Nota: en 1625 no se despachó la flota porque el virrey tenía noticias de la presencia de navíos holandeses en el Pacífico y decidió no arriesgar la plata. Carta del virrey de Perú a su majestad, Lima, 23 de junio de 1625, incluida en la consulta del Consejo de Indias, Madrid, 13 de diciembre de 1625, en AGI, Indiferente, 755.

Fuente: elaboración propia con base en TePaske y Klein, Royal, 1982, t. I, pp. 296-335; Báncora, "Remesas", 1959, pp. 85-86, y Rodríguez, "Caudales", 1964.

virreinal, que en cierto modo respondía a la decisión del virrey y de la corona.

$\mathrm{Al}$ igual que los ingresos, los egresos de las Cajas Reales indianas también contaban con numerosos rubros, aunque muy pocos ejercían una influencia decisiva. Existían siete partidas principales: guerra y defensa; remitido a Castilla; extraordinario; salarios y administración; subvención a la minería; devolución de préstamos, y gastos sociales y caritativos. Según TePaske, entre 1581 y 1700, los egresos de la Caja de Lima se distribuyeron de la siguiente manera: remitido a Castilla (39\%); defensa (26\%); extraor- 
dinario (17\%); subsidios a la minería (9\%); administración (6\%), y gastos sociales, caritativos y religiosos (4 por ciento). ${ }^{45}$

Para las décadas que nos interesan hemos realizado un análisis que nos revela uno de los motivos del incremento de las remesas. Tal como muestra el cuadro 2, los principales egresos de la Caja de Lima durante el virreinato del conde de Chinchón correspondieron, en orden decreciente, a las remesas a España, los gastos defensivos, los subsidios a Huancavelica, el rubro extraordinario y el mantenimiento de la administración. El cambio fundamental entre el perfil de egresos del periodo anterior -que se recuperó durante la segunda mitad de la década de 1640- fue la disminución de los gastos defensivos, circunstancia que naturalmente tuvo su correlato en las remesas a Castilla. Durante la década de 1630, aquellos pasaron de representar 30\% de los egresos netos totales a situarse en 22\%, mientras que lo enviado a la península alcanzó $51 \%$, superando en once puntos los valores del lustro 1625-1629. Conviene apreciar que esta variación respondió a una política deliberada de retracción y racionalización de los gastos defensivos, que logró contener un incremento interrumpido de tres décadas; también, hay que advertir que la disminución se produjo en un contexto de guerra, en el que el aparato defensivo del virreinato, especialmente en la vertiente pacífica, recibió algunas mejoras.

En la coyuntura específica de la primera mitad del siglo XVII, los gastos defensivos de la Caja de Lima constituyeron uno de los apartados fiscales que mayor incidencia tuvo en la distribución de los egresos de esta tesorería. Esta circunstancia se fue acentuando conforme avanzaba la centuria y se reducían las remesas, tanto las exteriores a Castilla como las internas a los distritos mineros, convirtiéndose en uno de los ramos sobre el cual descansaba la posibilidad de enviar más o menos plata a España. De hecho, las erogaciones propias de la estructura bélica del virreinato no rivalizaban con ninguna otra, a excepción de las remesas a la península. Con estas últimas, en cambio, tenían una estrecha relación, que quedó de manifiesto con el movimiento que experimentó cada uno de estos ramos durante las décadas del valimiento de Olivares.

Como se sabe, durante los años del conde-duque de Olivares resultó impostergable la adopción de medidas que incrementaran la capacidad defensiva del virreinato de Perú y de toda América en general. En concreto, se fortaleció la presencia militar en el Caribe y en el océano Pacífico y se abordó una serie de construcciones defensivas que, en conjunto, representaron un esfuerzo defensivo de gran envergadura. ${ }^{46}$ De cualquier manera, desde la Corte de Madrid este intento de adaptar la estructura defensiva

${ }^{45}$ Véase TePaske, “Cost”, 1993, pp. 1-33.

${ }^{46}$ Véase Israel, “Olivares”, 1990, p. 279. 


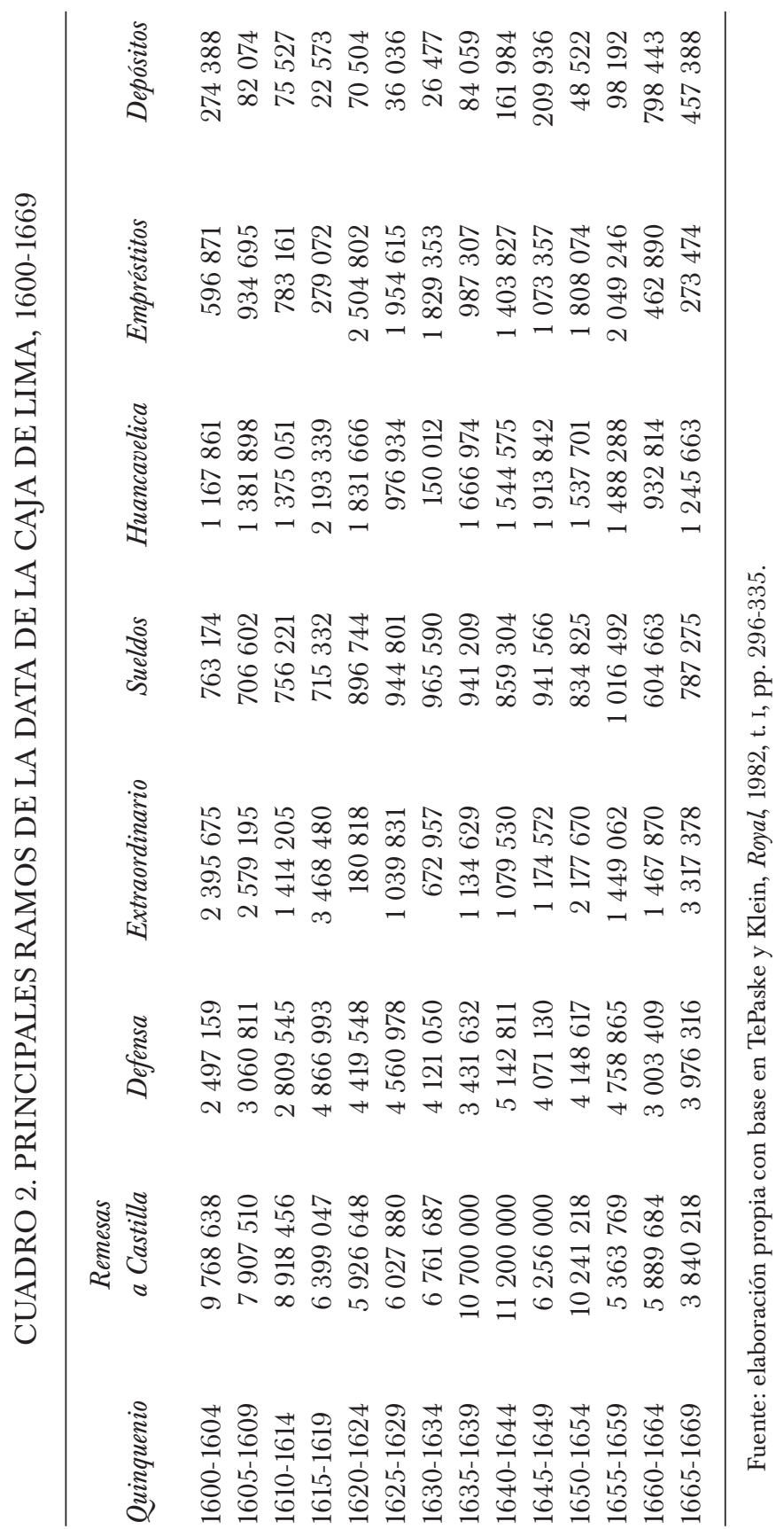


a la nueva situación estuvo presidido de gran prudencia en el control del gasto. De hecho, los frecuentes encargos de economía que solían hacerse a todos los virreyes y los mecanismos de control del gasto adquirieron un especial significado en la coyuntura concreta de los años que nos ocupan en la que se estableció una relación problemática entre las necesidades del ámbito local, las de la corona en Europa y la crisis fiscal virreinal. ${ }^{47}$ Puede hablarse de una tensión no resuelta entre intereses que indudablemente tenían puntos en común, concretamente la defensa eficaz del virreinato, pero divergentes en lo que respecta a la distribución de las cargas de la defensa y de los excedentes de la Caja de Lima. En esta dinámica, los virreyes debieron actuar armonizando estos intereses y sopesando las necesidades de cada una de las partes en momentos concretos para adoptar decisiones que afectaban el equilibrio entre el dinero que permanecía en el virreinato y el que se enviaba a Castilla.

El conde de Chinchón resultó, desde la perspectiva de la corona, un hábil gestor de este antagonismo. En un contexto de amenaza de incursión holandesa -que nunca llegó a materializarse- consiguió revertir por única vez en toda la centuria el incremento de los gastos defensivos respecto de las sumas remitidas a Castilla, aunque sin descuidar demasiado las necesidades militares del virreinato. ${ }^{48}$ Por el contrario, la gestión del marqués de Mancera tuvo un signo distinto. En un marco de incremento de los ingresos de la Hacienda como resultado de las medidas fiscales asentadas por su antecesor, el último virrey del valimiento de Olivares se inclinó decididamente por el aumento de los recursos y las estructuras defensivas virreinales frente al ahorro encomendado desde Madrid. Cuando en la península se tuvo noticia de estas medidas se ordenó reducir el gasto, aunque la política de hechos consumados del virrey impidió bloquear cualquier reacción desde la Corte.

Pero este no era el único elemento que determinaba las remesas a Castilla, puesto que la disminución transitoria de los gastos defensivos del quinquenio 1635-1639, sumada al incremento de los ingresos netos, no explican los niveles alcanzados por las remesas entre 1635 y 1644 . Teniendo en cuenta que los ingresos netos y los gastos netos presentan sumas semejantes, puesto que se enviaba a España todo el dinero que no fuera aplicado a los gastos locales, es preciso detenerse en los cambios en la composición de los egresos (véase gráfica 5).

\footnotetext{
${ }^{47}$ La importancia dada por la corona a la economía de gasto, especialmente al de carácter defensivo, puede verificarse en las instrucciones dadas a los virreyes para guiar su gestión. Véanse las de Chinchón y Mancera en Hanke, Virreyes, 1978, tt. II-III.

${ }^{48}$ Fernández, "Relación", 1978, pp. 69 y ss. y 78 y ss.
} 


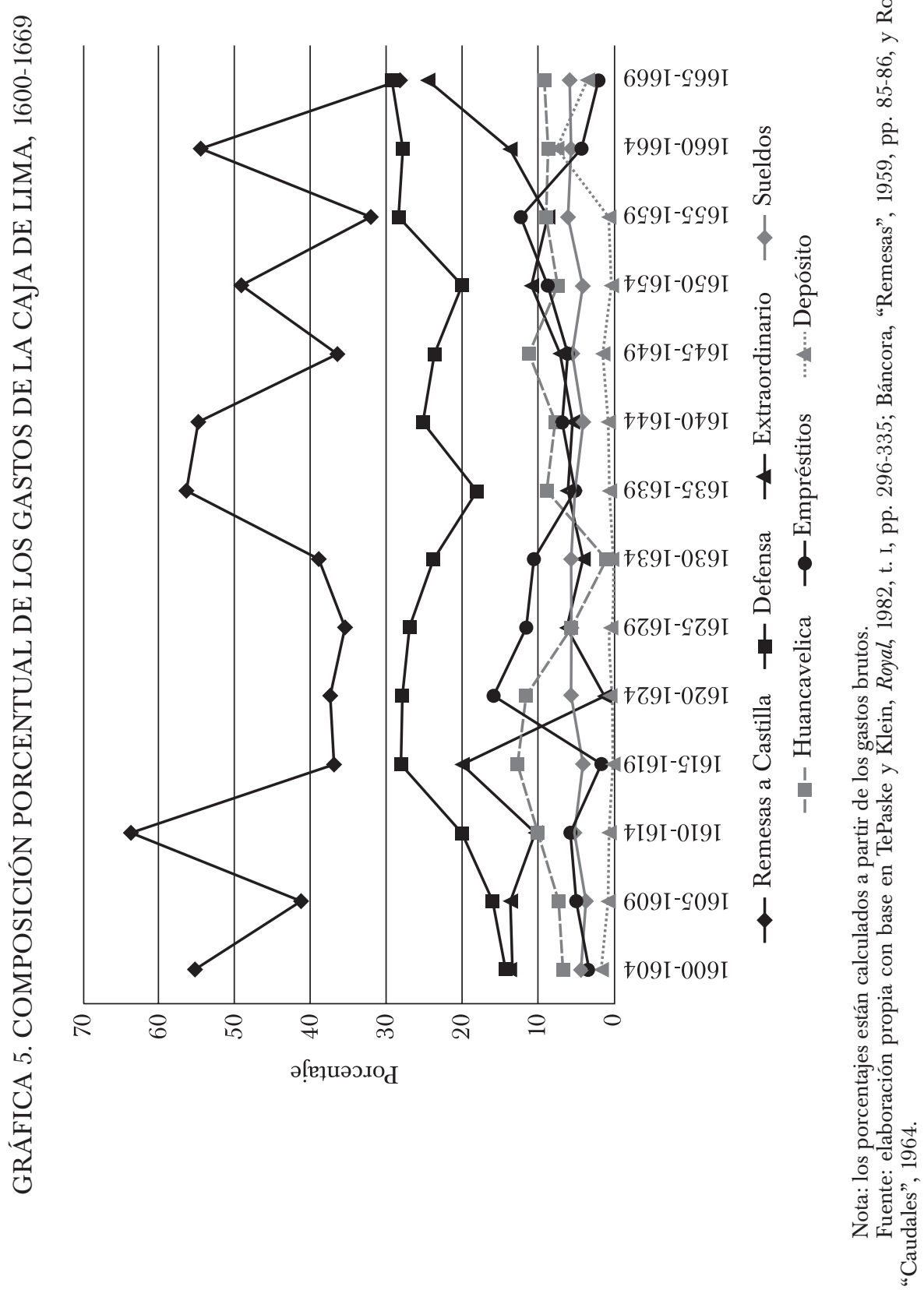


Según hemos explicado, durante los años del conde-duque de Olivares se produjo la creación de nuevos ramos en el apartado de los ingresos, al mismo tiempo que se incrementó el rendimiento de otros ya existentes. De este modo se logró soslayar temporalmente la dependencia que tenían las remesas a Castilla de las sumas recibidas de los distritos altoperuanos. Como hemos señalado, todos esos rubros, asociados a la fiscalidad del periodo comprendido entre 1625 y 1645 , estaban destinados a la península. De hecho, las sumas enviadas a España no sólo se registraban bajo la denominación "remitido a Castilla", sino que también se debían incluir, por cuenta aparte, los siguientes rubros: composiciones, Unión de Armas, venta y renunciación de oficios, media anata, papel sellado, juros, tributos vacos, nieve y aloja, Bula de la Santa Cruzada, vacantes de obispados y mesada eclesiástica. ${ }^{49}$ En valores corrientes, los cambios introducidos durante el valimiento del conde-duque de Olivares provocaron que las remesas reales experimentasen un aumento de algo más de 4000000 de pesos de ocho. Los ingresos netos, por su parte, se incrementaron en 3100000 pesos. Los gastos militares, sin embargo, que habían descendido entre 1635 y 1640 , sufrieron un nuevo aumento en el quinquenio siguiente. De modo que la única forma de explicar la diferencia, que no acaba de completarse con el aumento de los ingresos y la variación de los gastos militares, es con la asignación del ramo extraordinario de la Real Hacienda. Como recordamos, este rubro incluía todos aquellos ingresos o gastos para los que no existía un ramo específico. A pesar de haber tenido un carácter irregular durante las primeras décadas del siglo, a partir de 1635 marcó una firme tendencia al alza que no se interrumpió hasta 1670.

A partir de 1645, y especialmente después de 1650, la disminución de los recursos enviados desde Lima a la península respondió a la caída de los ingresos de su Caja Real, provocada tanto por la contracción de lo "venido de afuera" como por la reducción de algunos de los ramos cuyos montos se vinculan a los años de Olivares como la Unión de Armas, las composiciones de tierras, la media anata, los donativos, los tributos vacos, el estanco de la nieve o los censos. Durante la segunda mitad del siglo, los egresos totales, incluyendo las remesas a Castilla, muestran una tendencia decreciente, mientras que los principales rubros de gastos en el interior del virreinato se mantuvieron constantes $\mathrm{o}$, a lo sumo, presentaron pequeñas variaciones. ${ }^{50}$ Con lo cual se concluye, por un lado, que las autoridades locales contaban con un grado de maniobra bastante estrecho para reducir los gastos en el ámbito local, circunstancia que se fue acentuando aún más con el correr de los años. Por otro lado, cabe deducir que los envíos a la

\footnotetext{
${ }^{49}$ Escalona, Gazophilacium, 1775, libro II, parte II.

${ }^{50}$ TePaske, "Cost", 1993, pp. 10-11.
} 
península sólo podían producirse después de que los ingresos hubieran alcanzado un umbral bastante consolidado, que se aplicaba a los gastos fijos, ${ }^{51}$ es decir, que "la crisis fiscal minera fue transferida a España" ${ }^{52}$ En este contexto, los oficiales reales, forzados en buena medida por las circunstancias, habían establecido como norma el incumplimiento de las órdenes que tenían. Así, pese a que estaban obligados a enviar a la península lo remitido desde las Cajas de Potosí, Oruro y La Paz, lo cierto es que esto rara vez se cumplió "porque los gastos que se hacen no se pueden suplir en otra parte"..$^{53}$

\section{Fiscalidad y gestión política}

El saneamiento de la Real Hacienda, "nervio de la autoridad" como la calificaba Olivares, fue un objetivo central de sus planes reformistas. Su intención residía en consolidar una fiscalidad que guardara relación con las cargas a las que estaba sometida la monarquía. El conde-duque de Olivares aspiró a establecer, al menos en Castilla, unos ingresos fijos por medio de mecanismos constantes e independientes de las Cortes y demás instancias intermedias. ${ }^{54}$ Sin embargo, en el ámbito virreinal peruano, la dinámica de los principales egresos de la Caja de Lima, la crisis fiscal de la minería, la evolución porcentual entre lo recibido y lo remitido a Castilla, el incremento de los ingresos y, sobre todo, la naturaleza de estos últimos, inducen a interpretar la fiscalidad del periodo de Chinchón, y en buena medida también del marqués de Mancera, desde el punto de vista político que asuma la interacción entre la administración colonial y los grupos de poder local.

Además de ser susceptible de utilizarse, con los debidos reparos, como indicador de la actividad económica, la fiscalidad también puede servir para comprobar la salud del nexo político entre la corona y los virreinatos americanos. Y es esta cuestión, precisamente, la que estimo esencial para comprender las características de la fiscalidad indiana del periodo del conde-duque de Olivares y del virreinato del conde de Chinchón. Más allá de que la recaudación colonial se asentara sobre la actividad económica real, también poseía un componente político que ejercía gran incidencia en el resultado total de los ingresos y de las remesas. Por este hecho, en el contexto concreto que nos ocupa, la caída de los ingresos estaría mos-

${ }^{51}$ Véanse Andrien, Crisis, 1985, p. 67, y Slicher, Real, 1989, p. 104.

${ }^{52}$ Véanse Noejovich, "Economía”, 1997, p. 327, y Rodríguez, "Caudales", 1964, pp. 23-24.

${ }^{53}$ López, Noticia, 1989, t. VI, p. 85. Para una relación entre lo enviado a Lima desde Potosí y Oruro y lo remitido a Castilla puede consultarse a Andrien, Crisis, 1985, pp. 62, 67.

${ }^{54}$ Elliott y Peña, Memoriales, 1978, t. I, pp. 20-23, y Gelabert, "Evolución”, 1998, p. 280. 
trando más que un fenómeno económico, la pérdida de la capacidad de la corona de obtenerlos en el virreinato de Perú. ${ }^{55}$ Descartada la crisis de la actividad minera, sobre todo para las décadas que nos atañen, resulta bastante claro que el mantenimiento de los ingresos de la Caja de Lima y el aumento de las remesas reales, como respuesta a las presiones ejercidas por el favorito real desde Madrid, dependió, en gran medida, del manejo político realizado en la sede virreinal y de las relaciones de poder de la administración con la elite local. Esta circunstancia correspondía tanto a la imposición de nuevas cargas como a la asignación de los gastos, ya que, entre otras cosas, no resultaba una medida popular que los virreyes quitasen recursos a la defensa local para destinarlos a la financiación de la política dinástica europea. ${ }^{56}$

Si acaso fuera posible calificar de exitosa la avanzada fiscal que tuvo lugar en Perú a partir de 1625, lo cierto es que no se trató de una tendencia firmemente establecida en todos los distritos fiscales del virreinato, ni de un incremento que perdurase en el tiempo. En el largo plazo, tanto los ingresos de la Caja de Lima como las remesas a Castilla mostraron una relación muy estrecha con lo ocurrido en términos fiscales en los distritos mineros. Hemos referido ya la incapacidad de la Real Hacienda de mantener una recaudación consecuente con el ritmo de la producción argentífera. Pero también habría que agregar que la reducción no sólo estuvo originada por el descenso de los ingresos, sino también por un incremento de lo retenido en los distritos fiscales subordinados. ${ }^{57}$ Estos hechos, contrapuestos a lo ocurrido en Lima, nos estarían revelando una geografía de la capacidad de imposición o del grado de control de los oficiales reales virreinales. ${ }^{58}$

En la capital virreinal, en cambio, fue donde se produjo un incremento de los ingresos que compensó transitoriamente la caída de lo "venido de afuera". Esta compensación se produjo mediante una doble sustitución de ingresos, geográfica y cualitativa, que no fue sino un indicador de la naturaleza precaria del incremento fiscal conseguido en tiempos de Olivares.

${ }^{55}$ Suárez, Desafíos, 2001, p. 5.

${ }^{56}$ En este sentido, por ejemplo, fray Buenaventura de Salinas y Córdoba denunciaba "que Flandes cuesta a su majestad más de 284000000 de oro y plata y más de 350000 hombres; y yo digo, y todos lo dirán, que la parte no puede recompensar lo gastado, cuanto más lo que va gastado. Pues mucho será que habiendo dado el Perú su sangre y su sustancia, fundida en tantos millones a sus reyes, lo menosprecien y se olviden del cuando lo apuran y combaten enemigos y entrando tantos por su estrecho nunca los siga en su favor España, y siempre le aten las manos a un virrey, para que no gaste en beneficio suyo". Salinas, Memorial, 1631, p. 255.

${ }^{57}$ Andrien, Crisis, 1985, p. 63.

${ }^{58}$ En este sentido resulta elocuente que el marqués de Mancera reconociera que los oficiales de Potosí no se atrevían a proceder contra los azogueros más poderosos y que solían esperar a que lo hiciera el virrey. Véase Toledo, "Relación", 1978, p. 162. La idea de la crisis fiscal estaba presente también en López, Noticia, 1989, t. IV, p. 6. 
Como se aprecia en el cuadro 1, durante la década de 1640 algunos de los ramos que más contribuyeron a sostener temporalmente los ingresos fueron los que -siguiendo a Andrien- podríamos denominar "nuevos impuestos". Entre ellos se encuentran las ventas y las composiciones de tierras y pulperías, la mesada, la media anata, el estanco de la nieve, la Unión de Armas y el papel sellado. Algunos de estos apartados tuvieron un carácter poco consistente, ya fuera por su naturaleza o por la caída de su montante provocado por diversos factores. Así, por ejemplo, las composiciones de tierras sufrieron una contracción muy acentuada hacia 1650, al igual que la media anata y la mesada eclesiástica. El rendimiento del estanco de la nieve, que nunca fue significativo, dependía del atractivo que pudiera suscitar y de la existencia o no de personas interesadas en pujar por él. Además, en 1655 dejó de aportar a la Real Hacienda. Con la Unión de Armas ocurrió algo semejante, ya que el monto de su recaudación, una vez que logró comenzar tras una larga negociación, dependió del Consulado de Lima y, además, a mediano plazo, esta contribución presentó una tendencia decreciente. Tampoco se debe soslayar que las principales cargas sobre el comercio -concretamente el almojarifazgo y las alcabalas-, firmemente establecidos para esta época, estaban asentadas en la comunidad mercantil asociada en dicha institución. Este hecho revela la aceptación, por parte de la corona, del pacto y el consenso con el Consulado, en un contexto en el que la evasión fiscal en el tráfico mercantil estaba alcanzando niveles excepcionales, como demostró la denuncia de Cristóbal de Balbas en 1626. En esta ocasión, el Consejo de Indias tuvo que reconocer sorprendido que "nunca se había juzgado que el exceso y atrevimiento hubiese podido llegar a tanto". ${ }^{59}$

Fue durante estos años cuando debido a la impresión poco favorable que se tenía en Madrid de la administración de la Hacienda en Perú, se propició un cambio en la forma de percibir los derechos fiscales. En la instrucción que se le entregó al conde de Chinchón, se le encomendó que "siempre que vuestra excelencia pudiere asegurarlas [rentas reales] por encabezamientos, asientos, arrendamientos, será más efectivo y suave porque las administraciones son costosas, sujetas a fraudes y a desconsuelos y rigores, si se hacen con el cuidado que se requiere". ${ }^{60}$ Aunque la administración indirecta solía asegurar unas sumas fijas y aligeraba las cargas de la Real Hacienda, lo cierto es que la negociación de las condiciones de los asientos, sobre todo en épocas de dificultades, podía significar una pérdida de la preeminencia de la corona y, por tanto, de su capacidad de alcanzar

\footnotetext{
${ }^{59}$ Suárez, Desafíos, 2001, p. 303. Sobre el caso de Cristóbal de Balbas puede consultarse Vila, "Ferias", 1982, pp. 275-340.

${ }^{60}$ Véase Fernández, "Relación”, 1978, p. 60.
} 
un acuerdo favorable. Además, estos contratos solían contener una serie de privilegios para los asentistas, que resultaron muy atractivos para el Consulado de Lima. ${ }^{61}$

Cabría enfatizar el carácter precario e irregular de los ingresos provenientes de los mecanismos financieros, que no sólo dependían de la respuesta favorable de los potenciales prestamistas, sino que a largo plazo, además, incrementaban los egresos. Como ha señalado Andrien, los juros lograron hacer coincidir una necesidad de la Real Hacienda con los intereses de una parte de la sociedad limeña, lo que sirve para explicar la buena acogida que tuvieron en todas las oportunidades en las que la corona los colocó en esta plaza. Desde 1639, los principales tomadores de los títulos ya no fueron los comerciantes, tal como había ocurrido hasta esa fecha; a partir de entonces, el endeudamiento tuvo lugar especialmente con instituciones religiosas y con las comunidades indígenas, lo que facilitó la gestión de los préstamos en la tesorería de Lima. ${ }^{62}$ Andrien planteó la hipótesis de que el incremento del endeudamiento de la Caja acentuó su dependencia de los grupos de poder local, lo que les habría dado una mayor capacidad de incidir sobre las instituciones de gobierno. ${ }^{63}$ En este marco hay que tener presente el papel esencial que desempeñaban los comerciantes limeños en el funcionamiento de la Hacienda Real. De hecho, dos de las mayores obligaciones financieras de la Caja de Lima, el situado de Chile y el subsidio de Huancavelica, dependían de los hombres de negocios que aseguraban su regularidad. Se trató de una circunstancia que a lo largo del siglo XVII se vivió también respecto de las remesas a Castilla. ${ }^{64}$

${ }^{61}$ Según refiere Margarita Suárez respecto de los asientos acordados con el Consulado de Lima, los comisarios de esta institución podían "nombrar a sus propios maestres de plata, decomisar las mercaderías llegadas subrepticiamente e inspeccionar los navíos que venían de cualquier punto del Pacífico. Asimismo, [...] podían abrir los fardos sospechosos de contrabando -cosa que nunca se les permitió a los oficiales reales- y, detalle importante, podían portar armas. Incluso en el asiento de 1635, el virrey accedió a que los mercaderes pudieran manifestar géneros prohibidos o llegados de contrabando en el Callao así que, mediante el pago de una suma, las mercaderías podían ser ingresadas legalmente en el virreinato.” Suárez, Desafíos, 2001, p. 302. El Consulado asumió la administración de la alcabala en 1619-1621, 1622, 1623-1631 y 1632-1640, y la del almojarifazgo en 1621-1624 y 1635-1637. Para el caso novohispano véase Celaya, "Cesión", 2010.

${ }^{62}$ Andrien, "Sale", 1981, pp. 6, 11-13.

${ }^{63}$ Ibid., p. 17.

${ }^{64}$ Véanse Pease y Noejovich, "Cuestión”, 2000, pp. 365-413, y Suárez, "Perú", 2009, pp. 254 y ss. Como ejemplo de esto puede tomarse el testimonio de López de Caravantes, quien refiere que en el año 1632 el virrey conde de Chinchón "mandó a los oficiales reales de la ciudad de Los Reyes dejasen de remitir [...] 164769 pesos de a ocho reales para las pagas de la gente de la Armada y presido y otras cosas necesarias, sin acordarlo en la Junta de Hacienda, donde se le pudiera decir lo dispuesto por su majestad y ejemplares de sus antecesores que tuvieron por de menos inconveniente pedir prestado en la república por tres meses lo necesario para cualesquiera gastos hasta que viniese de Potosí que no gravar la Real Hacienda en los intereses que por semejante retención hacían en España”. López, Noticia, 1989, t. VI, p. 85. 
Una periodicidad y un montante sumamente discontinuo tenían, también, la Bula de la Santa Cruzada, las ventas y renunciaciones de oficios y los préstamos graciosos. Durante la década de 1630, estos últimos prácticamente alcanzaron 3\% de los ingresos totales de la Caja limeña. Sin embargo, la ecuación política que generaban tenía unas consecuencias arriesgadas para el poder central de la monarquía y, en cierta forma, también para sus representantes locales. Por su parte, la venta de oficios abrió la puerta a una mayor participación de las elites locales en el ejercicio del poder y, en definitiva, a la erosión del control que se ejercía desde Madrid sobre el virreinato.$^{65}$ En esta misma línea podría incluirse el incremento de la presión fiscal sobre la administración por medio de la media anata, que representaba una carga importante sobre la remuneración de los oficios. Esta situación estaba agravada por el hecho de que una parte de la contribución debía abonarse por adelantado, con lo cual ya desde el comienzo existían motivos para que quienes ingresaban a la administración procuraran resarcirse económicamente mediante el usufructo de su posición.

\section{Conclusiones}

De lo dicho hasta aquí cabe deducir que el análisis cualitativo del incremento de los ingresos de la Caja de Lima revela varios elementos que explican su carácter precario. No cabe duda de que el régimen de Olivares resultó efectivo, al menos a corto plazo, en transferir recursos del virreinato de Perú a la península para sufragar los gastos de la costosa política dinástica que la corona sostenía en Europa. Claro que esta política exitosa en el ámbito local se contrapone con la incapacidad de mantener la plata dentro del mundo hispánico. Pero no tardaron en dejarse sentir en América los síntomas del agotamiento de esta "nueva" fiscalidad. En este sentido, tanto los ingresos ordinarios como los extraordinarios que hicieron posible el aumento de los ingresos, su mayor libertad respecto de lo "venido de afuera" y el incremento de las remesas de plata, perdieron rápidamente su potencial. Como se ha afirmado, la única excepción la constituyó el rubro extraordinario de la Real Hacienda. Algunos de los ramos que más se incrementaron tuvieron una vigencia temporal muy circunscrita, o un margen de crecimiento muy limitado. Incluso, una porción de los ingresos procedía, precisamente, de cargar a quienes tenían la responsabilidad de ejecutar la avanzada fiscal propiciada desde Madrid. Además, ramos como los préstamos, los servicios graciosos y, fundamentalmente, la venta de oficios socavaban la capacidad de acción de la administración y, en el

${ }^{65}$ Andrien, "Sale”, 1982. 
corto plazo, incluso complicaban aún más la situación de la Real Hacienda. Así, la dinámica del avance fiscal y contributivo brindó elementos a las elites locales para afianzar su mayor participación en el ejercicio del poder, sancionándose una tendencia contrapuesta a las intenciones del régimen del conde-duque de Olivares, que procuró implantar el hábito de la obediencia inspirado en el pensamiento de Justo Lipsio en la relación entre el monarca y sus súbditos.

Por su parte, no conviene soslayar que la aquiescencia de los grupos de poder local resultó decisiva en varios momentos del incremento fiscal. Según hemos visto, la puesta en ejecución de las nuevas imposiciones no estuvo exenta de un proceso de negociación. Cabría recordar que algunos grupos de poder de la capital virreinal participaban decisivamente tanto de la recaudación como de la definición del montante de ciertos rubros.

En definitiva, puede concluirse que el aumento de los ingresos fiscales, alcanzado por medio de los mecanismos señalados, constituyó un impasse, conseguido a fuerza de gestión política, del control del gasto y de la redistribución de los rubros que componían la data. Este periodo se insertó en un proceso de larga duración de pérdida de la capacidad de la Real Hacienda de mantener sus ingresos en las Indias. La presión ejercida desde Madrid y transmitida por sus representantes locales resultó efectiva en el corto plazo, sobre todo en el centro mismo del poder virreinal. Con el correr de los años, no sólo se produjo un descenso muy acusado de la fiscalidad de los distritos mineros, sino también una pérdida de efectividad de las cargas y los mecanismos introducidos durante el virreinato del conde de Chinchón. Pese a que la presión respondió mejor en la capital virreinal, ni era posible ni se contempló en ningún momento efectuar un reemplazo de la base fiscal del virreinato. Durante el siglo XVII, esta continuó asociada a las sumas obtenidas en las Cajas mineras. Llegados hasta aquí parece evidente que, en términos fiscales, el valimiento de Olivares representó un último intento transitorio de revertir la crisis fiscal que, aunque para estos años estaba mostrando sus primeras manifestaciones, no haría sino aumentar conforme avanzara la centuria, acentuando la pérdida del control político del poder central sobre el virreinato de Perú. En este sentido, los límites económicos y, en definitiva, políticos que se opusieron al incremento de la presión fiscal quedaron claramente establecidos. 


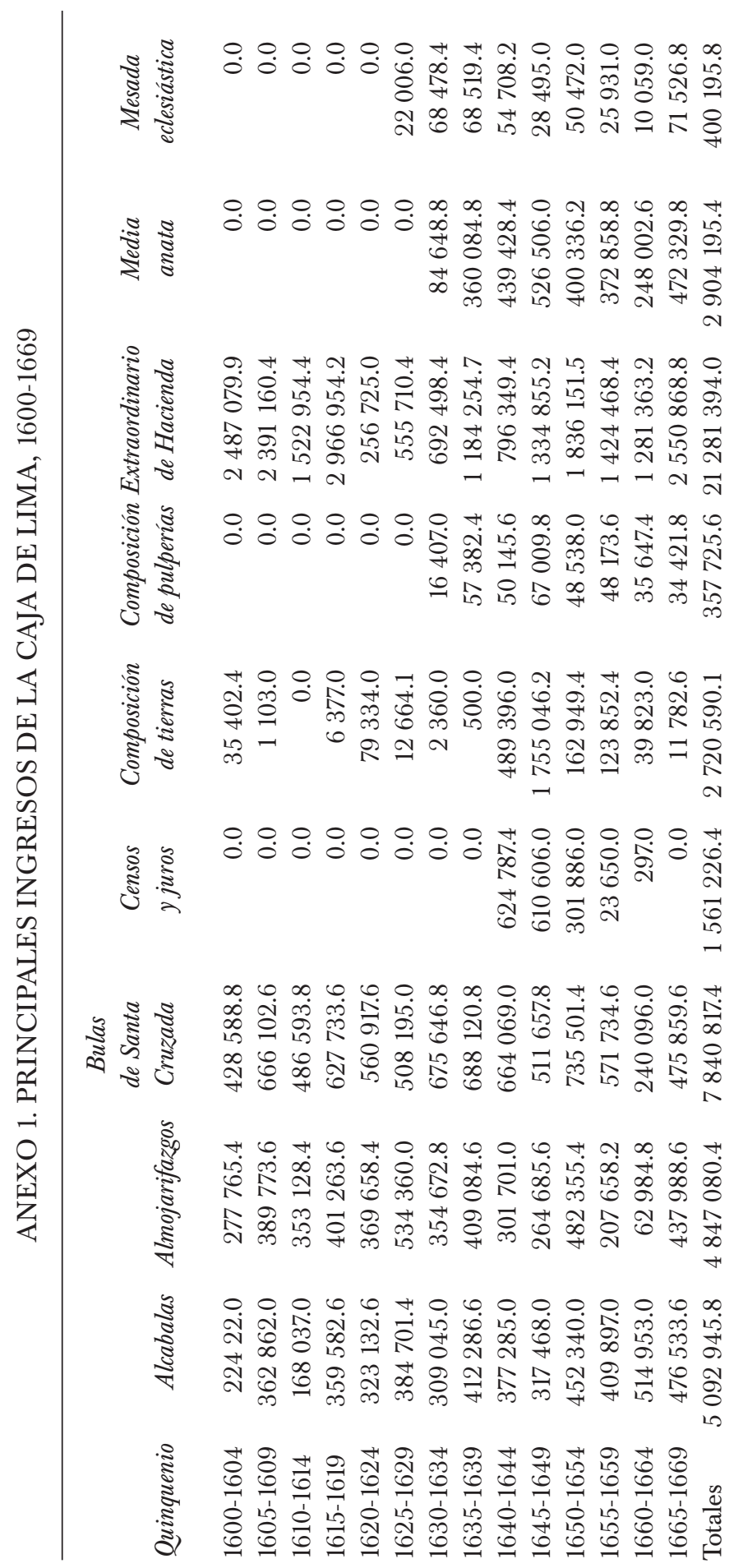




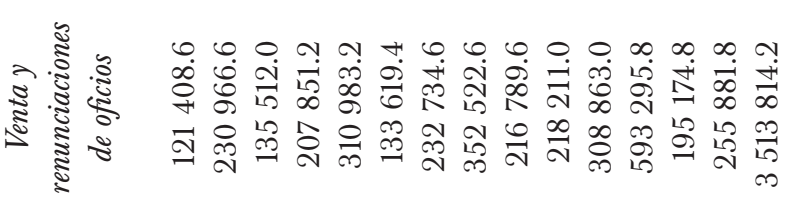

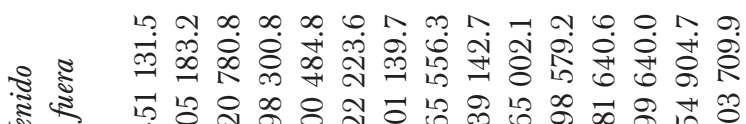
ฐ $\exists m$ 그

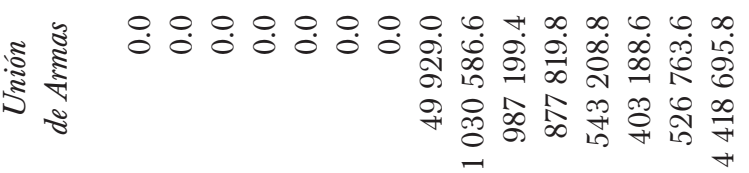

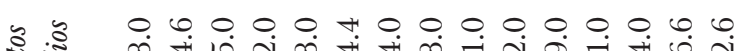

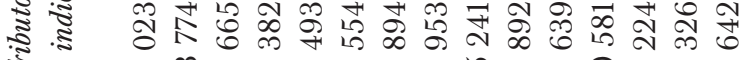
踏

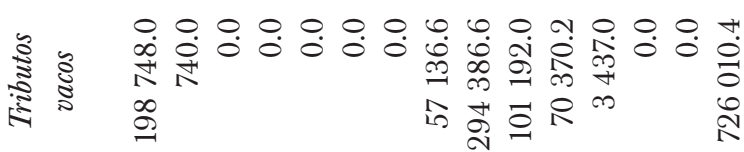

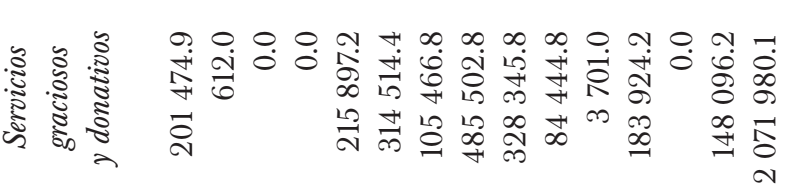

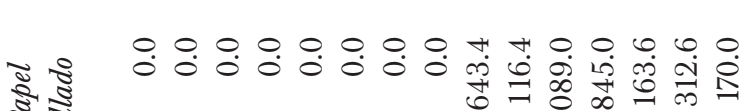
约

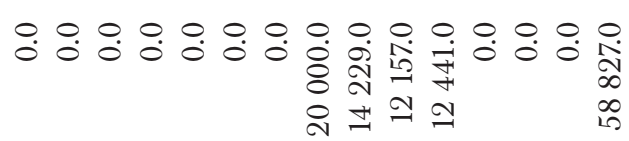

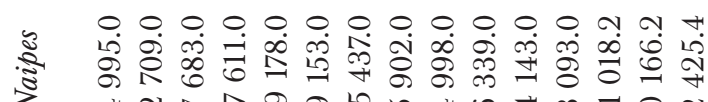

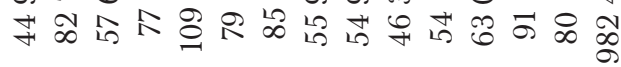

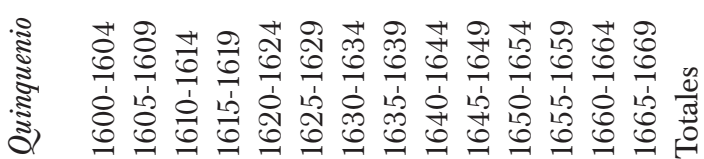




\section{FUENTES CONSULTADAS}

\section{Archivo}

AGI Archivo General de Indias, Sevilla.

\section{Bibliografía}

AmAdori, Arrigo, "Privanza, patronazgo y fiscalidad indiana en la Corte de Madrid durante el reinado de Felipe IV (1629-1631)", Revista Complutense de Historia de América, Universidad Complutense de Madrid, vol. 34, 2008, pp. 63-84.

, Política americana y dinámicas de poder durante el valimiento del conde-duque de Olivares (1621-1643), Madrid, Servicio de Publicaciones de la Universidad Complutense, 2011.

"El mayor vínculo de los imperios. Patronazgo y clientelismo en el gobierno de las Indias bajo el conde-duque de Olivares" en José MARía Imízcoz (ed.), Patronazgo y clientelismo en la monarquía hispánica (siglos XVI-XVIII), Vitoria, Universidad del País Vasco, en prensa.

Andrien, Kenneth, "The Sale of Juros and the Politics of Reform in the Viceroyalty of Peru, 1608-1695", Journal of Latin American Studies, Cambridge University Press, vol. 13, núm. 1, 1981, pp. 1-19.

"The Sale of Fiscal Offices and the Decline of Royal Authority in the Viceroyalty of Peru, 1633-1700", Hispanic American Historical Review, Duke University Press, vol. 62, núm. 1, 1982, pp. 49-71.

Crisis and Decline. The Viceroyalty of Peru in the Seventeenth Century, Albuquerque, University of New Mexico Press, 1985.

Assadourian, Carlos Sempat, El sistema de la economía colonial. Mercado interno, regiones y espacio económico, Lima, Instituto de Estudios Peruanos, 1982.

Bakewell, Peter, "Registered Silver Production in the Potosí District, 1550-1735", Jahrbuch für Geschichte Lateinamerikas, Institut für Geschichte-Franzens Universität Graz, vol. 12, 1975, pp. 67-103.

"La minería en la Hispanoamérica colonial" en LesLie Bethell (ed.), Historia de América Latina, Barcelona, Crítica, 2000, t. 3, pp. 49-90.

Báncora Cañedo, Carmen, "Las remesas de metales preciosos desde el Callao a España en la primera mitad del siglo XVII", Revista de Indias, Consejo Superior de Investigaciones Científicas, vol. XIX, núm. 75, 1959, pp. 35-88.

Bernal, Antonio Miguel, España, proyecto inacabado. Los costes/beneficios del imperio, Madrid, Fundación Carolina/Centro de Estudios Hispánicos e Iberoamericanos/ Marcial Pons Historia, 2005. 
Brading, David y Harry Cross, "Colonial Silver Mining: Mexico and Peru”, Hispanic American Historical Review, Duke University Press, vol. 52, núm. 4, 1972, pp. 545-579.

Bronner, Fred, "La Unión de Armas en el Perú. Aspectos político-legales", Anuario de Estudios Americanos, Consejo Superior de Investigaciones Científicas, vol. XXIII, 1967, pp. 1133-1176.

, "Un agente extraordinario de Olivares para el Perú: el contador Hernando de Valencia”, Boletín del Instituto Riva-Agüero, núm. 10, 1975, pp. 29-62.

"Tramitación legislativa bajo Olivares. La redacción de los arbitrios de 1631”, Revista de Indias, vol. XLI, núms. 165-166, 1981, pp. 411-441.

Burkholder, Mark A. y Dewitt S. Chandler, De la impotencia a la autoridad. La corona española y las Audiencias en América, 1687-1808, México, Fondo de Cultura Económica, 1984.

Cañeque, Alejandro, "Cultura vicerregia y Estado colonial. Una aproximación crítica al estudio de la historia política de la Nueva España”, Historia Mexicana, El Colegio de México, vol. LI, núm. 1, 2001, pp. 5-57.

Celaya Nández, Yovana, "La cesión de un derecho de la Real Hacienda: la administración del impuesto de la alcabala novohispana en el siglo XVII. Tres estudios de caso", América Latina en la Historia Económica, Instituto de Investigaciones Dr. José María Luis Mora, núm. 33, enero-junio de 2010, pp. 93-125.

Céspedes del Castillo, Guillermo, América hispánica (1492-1898), Madrid, Marcial Pons, 2009.

Daniels, Christine y Michael Kennedy (eds.), Negotiated Empires. Centers and Peripheries in the Americas, 1500-1820, Nueva York y Londres, Routledge, 2002.

ElliotT, John, “América y el problema de la decadencia española”, Anuario de Estudios Americanos, Consejo Superior de Investigaciones Científicas, vol. XXVIII, 1971, pp. $1-23$. Crítica, 2004.

El conde-duque de Olivares. El político en una época de decadencia, Barcelona, y José De LA PeÑa (eds.), Memoriales y cartas del conde duque de Olivares, t. I, Madrid, Alfaguara, 1978.

Escalona y Agüero, GasPar de, Gazophilacium Regium Peribicum, Madrid, Typographia Blasii Roman, 1775 [1674].

Fernández de Cabrera y Bobadilla, Luis Jerónimo (Conde de Chinchón), "Relación del estado en que el conde de Chinchón deja el gobierno del Perú al marqués de Mancera" en Lewis Hanke (ed.), Los virreyes españoles en América durante el gobierno de la casa de Austria, Perú, Madrid, Atlas, 1978 [1640], t. III, pp. 34-85.

Fisher, John, "La producción metalífera" en Alfredo Castillero Calvo y Alan Kuethe (dirs.), Historia general de América Latina, t. III: 1, París y Madrid, Unesco/ Trotta, 2000, pp. 133-150.

Garavaglia, Juan Carlos, Mercado interno y economía colonial, Rosario, Prohistoria, 2008. 
García Bernal, Manuela Cristina, "Las elites capitulares indianas y sus mecanismos de poder en el siglo XVII", Anuario de Estudios Americanos, Consejo Superior de Investigaciones Científicas, vol. LVII, núm. 1, 2000, pp. 89-110.

Gelabert, JuAn, "La evolución del gasto de la monarquía hispánica entre 1598 y 1650. Asientos de Felipe III y Felipe IV", Studia Historica. Historia Moderna, Universidad de Salamanca, núm. 18, 1998, pp. 265-297.

HaNke, Lewis (ed.), Los virreyes españoles en América durante el gobierno de la casa de Austria, Perú, Madrid, Ediciones Atlas, 1978, tt. II-III.

Irigoin, Alejandra y Regina Grafe, "Bargaining for Absolutism: A Spanish Path to Nation-State and Empire Building", Hispanic American Historical Reviewe, Duke University Press, vol. 88, núm. 3, 2008, pp. 173-209.

Israel, Jonathan, Razas, clases sociales y vida política en el México colonial, 1610-1670, México, Fondo de Cultura Económica, 1996 [1975]. "Olivares and the Government of the Spanish Indies, 1621-1643" en Jonathan IsRael (ed.), Empires and Entrepots. The Dutch, the Spanish Monarchy and the Jeres, 1585-1713, Londres y Ronceverte, The Hambledon Press, 1990, pp. 265-285.

Kamen, Henry y Jonathan Israel, "The Seventeenth-Century Crisis in New Spain: Myth or Reality?, Past E Present, Oxford University Press, vol. 97, núm. 1, 1982, pp. 144-156.

KLeIn, HeRbert, Las finanzas americanas del imperio español. 1680-1809, México, Instituto de Investigaciones Dr. José María Luis Mora, 1994.

"Las finanzas reales" en AcAdemia Nacional DE la Historia, Nueva historia de la nación argentina, Buenos Aires, Planeta, 1999, t. 3, pp. 13-30.

y JaCQUes BARbier, "Recent Trends in the Study of Spanish American Colonial Public Finance”, Latin American Research Review, Latin American Studies Association, vol. III, núm. 1, 1988, pp. 35-62.

López de Caravantes, Francisco, Noticia general del Perú, Madrid, Atlas, 1985-1989, tt. IV-VI.

LynCH, John, Historia de España, Barcelona, Crítica, 2005, t. V.

Macera, Pablo, Los precios del Perú. Siglos XVI-XIX: fuentes, Lima, Banco Central de Reserva del Perú, 1992.

Maniau Torquemada, Joaquín, Compendio de la historia de la Real Hacienda de Nueva España, México, Universidad Nacional Autónoma de México, 1995 [1792].

Marichal Salinas, Carlos, "Rethinking Negotiation and Coercion in an Imperial State”, Hispanic American Historical Reviere, Duke University Press, vol. 88, núm. 3, 2008, pp. 211-218.

Martínez de Salinas Alonso, María Luisa, "La sala del papel sellado del Consejo de Indias" en Instituto Internacional de Historia del Derecho Indiano, Poder y presión fiscal en la América española (siglos XVI, XVII y XVIII): trabajos del VI Congreso del Instituto Internacional de Historia del Derecho Indiano en homenaje al Dr. 
Alfonso García-Gallo, Valladolid, Casa-Museo Colón/Seminario Americanista de la Universidad de Valladolid, 1986, pp. 455-464.

MorineAU, MicheL, Incroyables gazettes et fabuleux métaux: Les retours des trésors américains d'après les gazettes hollandaises (XVIe.-XVIIIe. siècles), París, Maison des Sciences de l'homme, 1985.

Moutoukias, Zacarías, Contrabando y control colonial en el siglo XVII: Buenos Aires, el Atlántico y el espacio peruano, Buenos Aires, Centro Editor de América Latina, 1988.

Muro Romero, Fernando, "La reforma del pacto colonial en Indias. Notas sobre instituciones de gobierno y sociedad en el siglo XVII", Jahrbuch für Geschichte Lateinamerikas, Institut für Geschichte Karl-Franzens Universität Graz, núm. 19, 1982, pp. $47-68$.

Noejovich, HÉctor, "La economía del virreinato del Perú bajo los Habsburgo y la denominada crisis del siglo XVII", Boletín del Instituto Riva-Agüero, núm. 24, 1997, pp. 319-341.

, "Caudales e imperio: una interpretación global en el mundo del siglo XVI-XVII” en Héctor Noejovich (ed.), América bajo los Austrias: economía, cultura y sociedad, Lima, Pontificia Universidad Católica del Perú, 2001, pp. 287-305.

, "Nivel de precios y actividad económica: comparaciones regionales en el virreinato del Perú (siglos XVI-XVII)", Fronteras de la Historia, Instituto Colombiano de Antropología e Historia, vol. 13, núm. 2, 2006, pp. 375-398.

Oliva Melgar, José María, "Pacto fiscal y eclipse de la contratación en el siglo XVII: Consulado, corona e indultos en el monopolio de Indias" en ANTONIO ACOSTA Rodríguez, Adolfo GonzÁlez Rodríguez y EnRIQueta Vila Vilar (coords.), La Casa de la Contratación y la navegación entre España y las Indias, Sevilla, Universidad de Sevilla/Consejo Superior de Investigaciones Científicas/Fundación El Monte, 2003, pp. 449-490.

Pease, Franklin y Héctor Noejovich, "La cuestión de la plata en los siglos XVIXVII”, Histórica, Pontificia Universidad Católica del Perú, vol. XXIV, núm. 2, 2000, pp. 365-413.

Pérez Herrero, Pedro, "Los beneficiarios del reformismo borbónico: metrópoli versus elites novohispanas", Historia Mexicana, El Colegio de México, vol. XLI, núm. 2, 1991, pp. 207-264.

Phelan, John Leddy, El reino de Quito en el siglo XVI, Quito, Banco Central de Ecuador, 1995. Ponce LeIVa, PILAR, Certezas ante la incertidumbre. Elite y Cabildo de Quito en el siglo XVII, Quito, Abya-Yala, 1998.

Recopilación de las leyes de los Reinos de Indias, Madrid, Julián de Paredes, 1681.

Rodríguez Vicente, María Encarnación, El tribunal del Consulado de Lima en la primera mitad del siglo XVII, Madrid, Ediciones Cultura Hispánica, 1960. "Los caudales remitidos desde el Perú a España por cuenta de la Real Hacienda. Series estadísticas (1651-1739)", Anuario de Estudios Americanos, Consejo Superior de Investigaciones Científicas, núm. 21, 1964, pp. 1-24. 
"El derecho de la media anata" en Instituto InTERnAcional DE HistoRIA Del Derecho Indiano, Poder y presión fiscal en la América española (siglos XVI, XVII y XVIII): trabajos del VI Congreso del Instituto Internacional de Historia del Derecho Indiano en homenaje al Dr. Alfonso García-Gallo, Valladolid, Casa-Museo Colón/Seminario Americanista de la Universidad de Valladolid, 1986, pp. 455-464.

Romano, Ruggiero, Coyunturas opuestas. La crisis del siglo XVII en Europa e Hispanoamérica, México, El Colegio de México/Fondo de Cultura Económica, 1993.

Mecanismos y elementos del sistema económico colonial americano. Siglos XVI-XVII, México, El Colegio de México/Fondo de Cultura Económica, 2004.

Salinas y Córdoba, Buenaventura, Memorial de las historias del Nuevo Mundo del Perú, Lima, Gerónimo de Contreras, 1631.

Slicher van Bath, Bernard, Real Hacienda y economía en Hispanoamérica, 1541-1820, Amsterdam, Centro de Estudios para el Desarrollo Laboral y Agrario, 1989.

SuÁrez Espinosa, Margarita, Comercio y fraude en el Perú colonial: las estrategias mercantiles de un banquero, Lima, Instituto de Estudios Peruanos/Banco Central de Reserva del Perú, 1995.

"La crisis del siglo XVII en la región andina" en Manuel Burga (ed.), Historia de América Andina, Quito, Universidad Andina Simón Bolívar, 2000, t. 2, pp. 289-318.

Desafíos trasatlánticos: mercaderes, banqueros y el Estado en el Perú virreinal, 1600-1700, Lima, Pontificia Universidad Católica del Perú/Fondo de Cultura Económica, 2001.

"El Perú en el mundo atlántico (1520-1739)” en Carlos Contreras (ed.), Compendio de historia económica del Perú, Lima, Banco Central de Reserva del Perú/ Instituto de Estudios Peruanos, 2009, t. 2, pp. 229-311.

TePaske, John Jay, "The Cost of Empire: Spendings Patterns and Priorities in Colonial Peru, 1581-1820", Colonial Latin American Research Review, Spanish Colonial Research Center-University of New Mexico, vol. 1, núm. 1, 1993, pp. 1-33.

y Herbert KleIn, The Royal Treasuries of the Spanish Empire in America, t. I: Perú, Durham, Duke University Press, 1982.

Toledo y Leiva, Pedro de (MARQués de Mancera), "Relación del estado del gobierno del Perú que hace el marqués de Mancera al virrey conde de Salvatierra" en LeWis Hanke (ed.), Los virreyes españoles en América durante el gobierno de la casa de Austria, Perú, Madrid, Atlas, 1978 [1648], t. III, pp. 140-196.

Vila Vilar, EnRIQUeta, "Las ferias de Portobelo: apariencia y realidad del comercio con Indias", Anuario de Estudios Americanos, Consejo Superior de Investigaciones Científicas, vol. XXXIX, 1982, pp. 275-340.

Yun Casalilla, Bartolomé, "Introducción. Entre el imperio colonial y la monarquía” en Bartolomé Yun CASAlilla (ed.), Las redes del imperio: elites sociales en la articulación de la monarquía hispánica, 1492-1714, Madrid, Marcial Pons, 2009, pp. 11-35. 